\title{
Methodological development from vehicle concept to modular body structure for the DLR NGC-Urban Modular Vehicle
}

Methodische Entwicklung vom Fahrzeugkonzept zur modularen Bauweise am DLR NGC-Urban Modular Vehicle

16. Internationales Stuttgarter Symposium 15.03.2016

Dipl.-Ing. Marco Münster

Dipl.-Ing. Michael Schäffer

Dr.-Ing. Ralf Sturm

Prof. Dr.-Ing. Horst E. Friedrich

Deutsches Zentrum für Luft- und Raumfahrt e.V. (DLR)

Institut für Fahrzeugkonzepte, Stuttgart

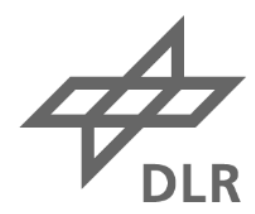

Knowledge for Jomorrow 


\section{Agenda}

- DLR Institute of Vehicle Concepts, Challenges and motivation for new vehicle concepts and Project Next Generation Car (NGC)

- Holistic development Methodology for vehicle concepts and body structures

- Development of the vehicle body structure for the electric Urban Modular Vehicle

- Prototypical validation of the floor crash concept

- Summary and Outlook 
DLR - German Aerospace Center Institute of Vehicle Concepts:

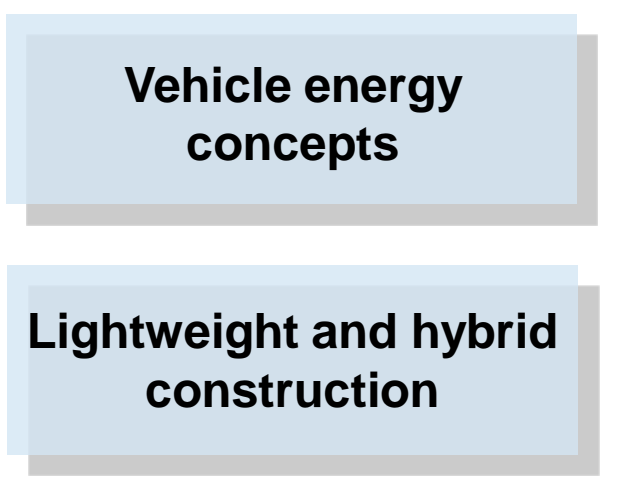

\section{Vehicle systems and technology assessment}

Alternative energy conversion

\section{Vehicle energy concepts}

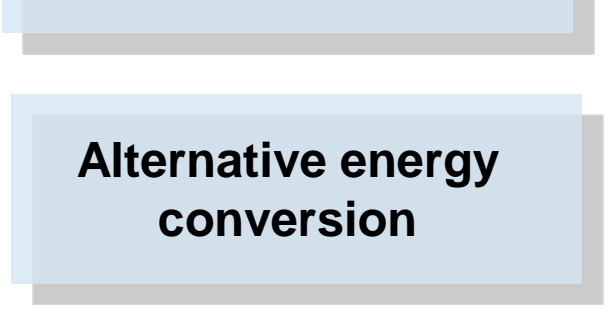

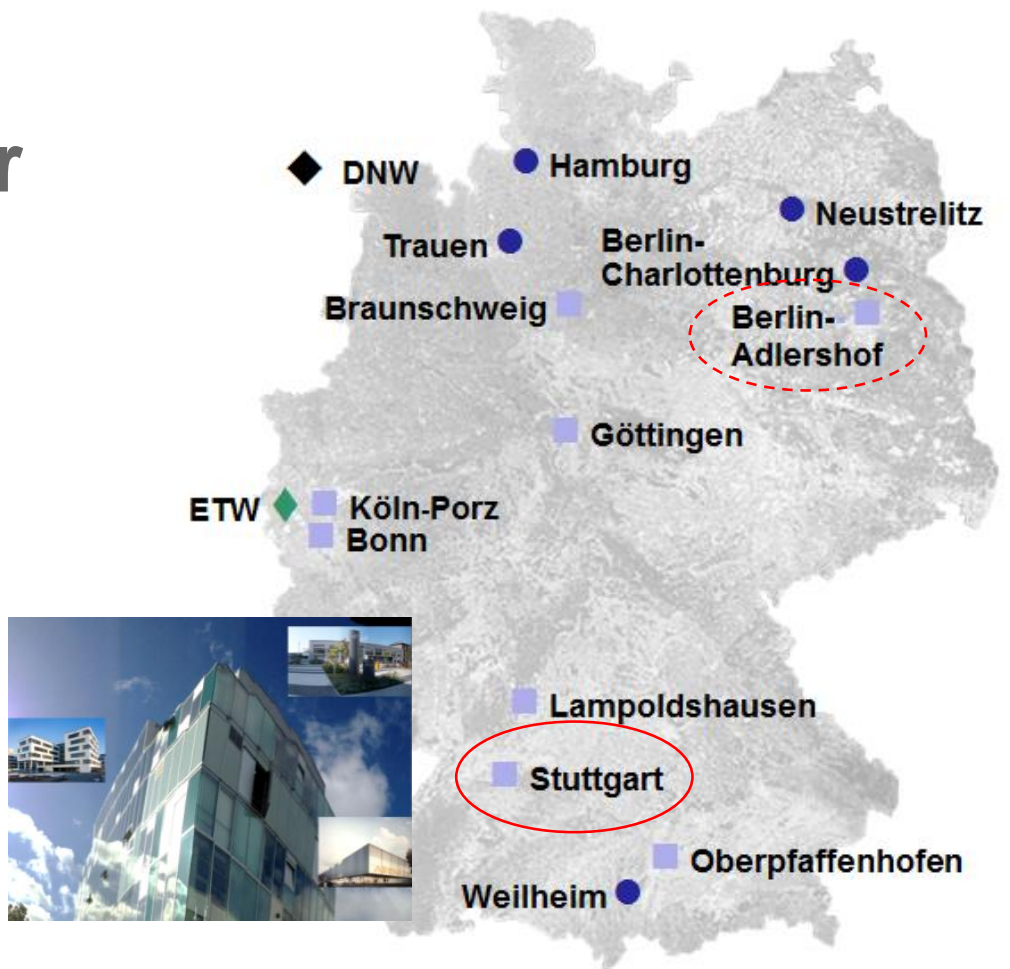

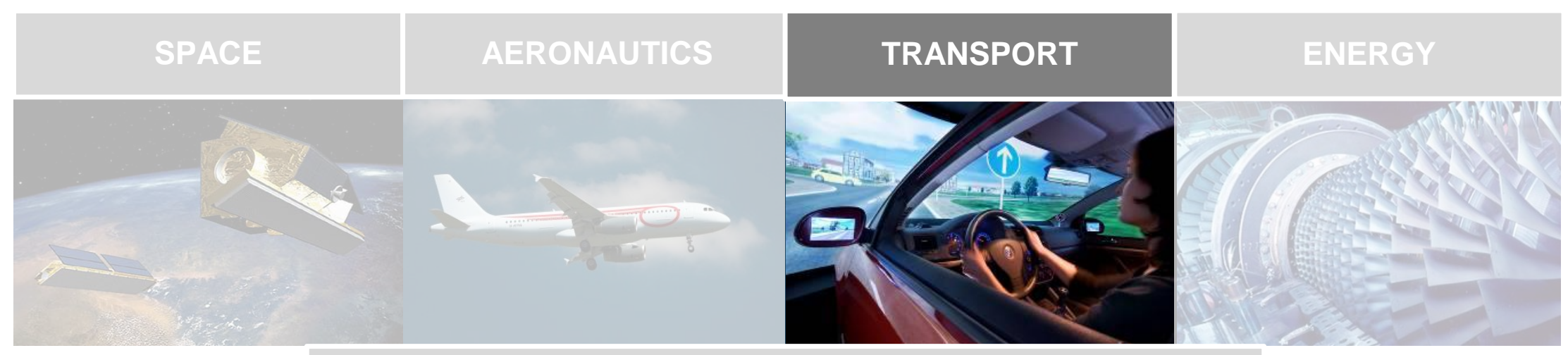

SECURITY

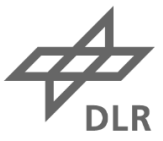




\section{Challenge and motivation}

Packaging conventional- and electric vehicle

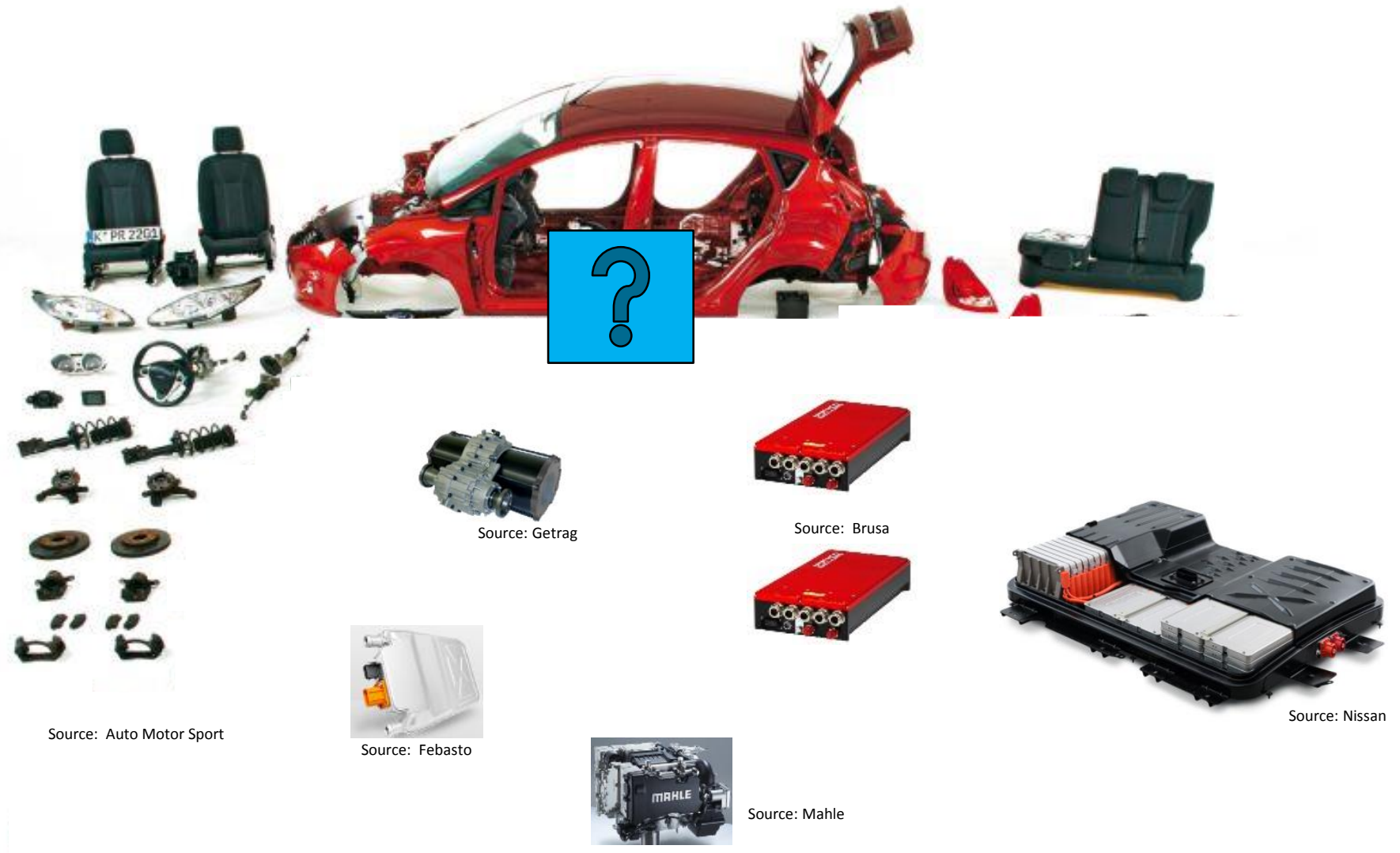

- remove:

combustion engine, exhaust system, transmission ...

- add: battery, electric motor, power electronics ...

Conclusion $\rightarrow$ Development of new vehicle concepts, components, BIW 


\section{DLR Next Generation Car (NGC)}

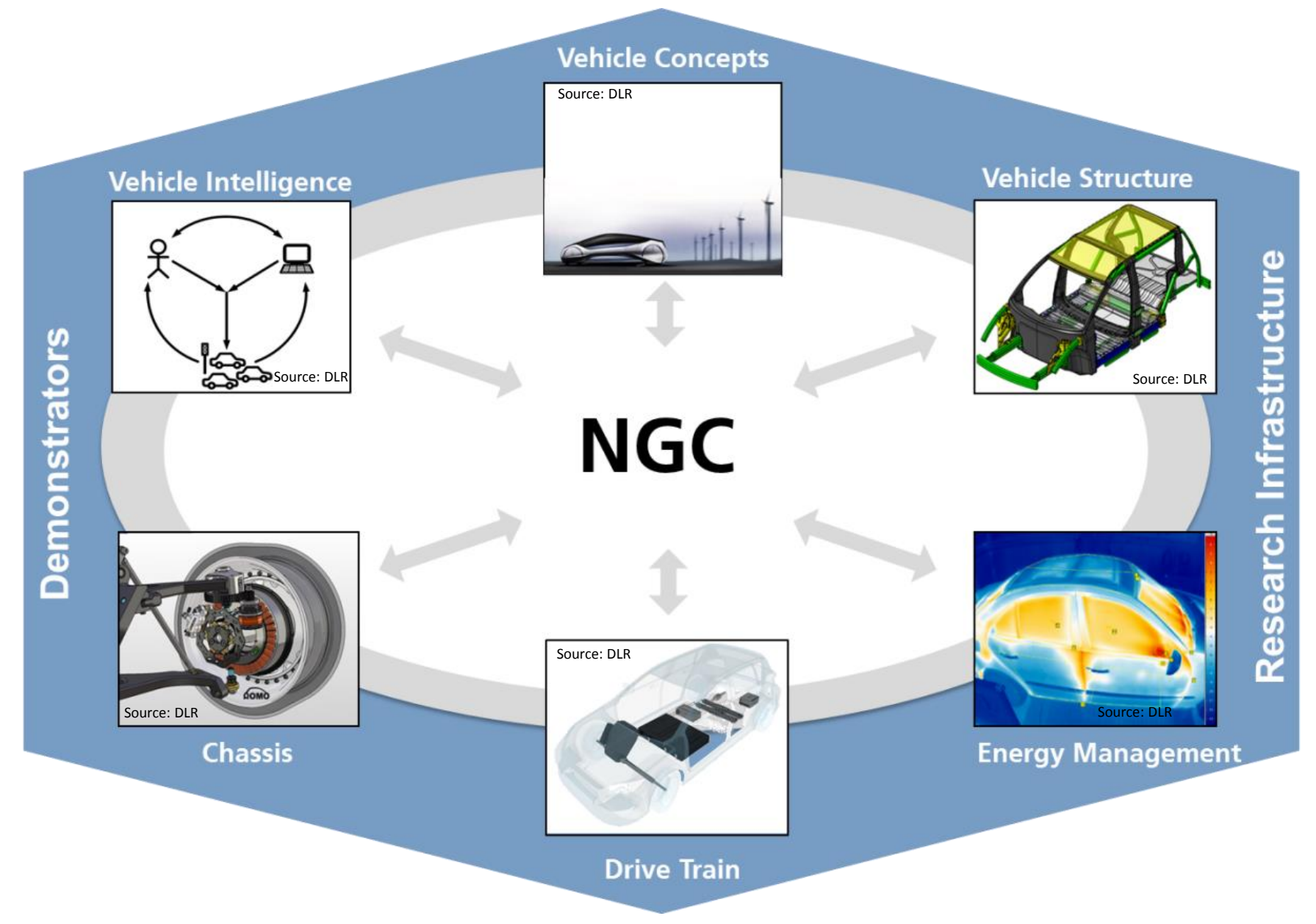

- Technologies, methods and tools for integrated development of road vehicles of tomorrow

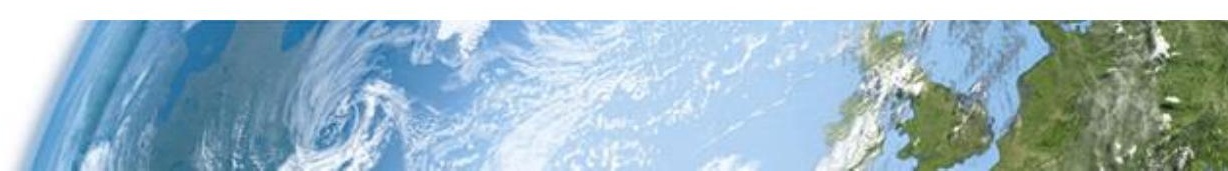




\section{DLR Next Generation Car (NGC) Concepts}

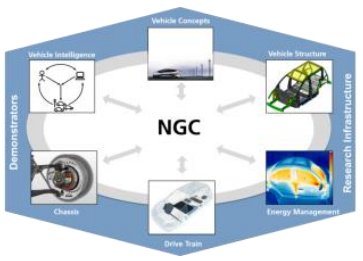

Urban Modular Vehicle (UMV)
Interurban Vehicle (IUV)
Save Light Regional Vehicle (SLRV)

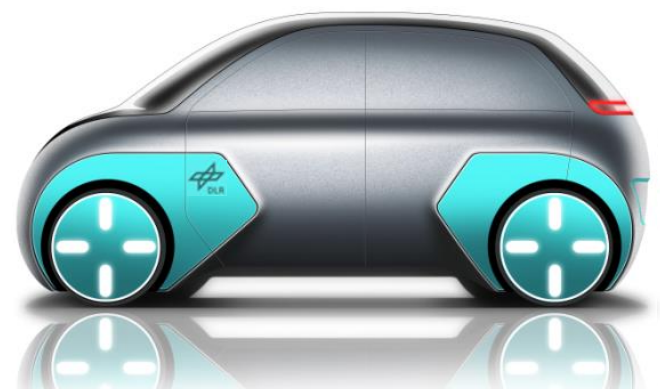

Electric, intelligent, modular

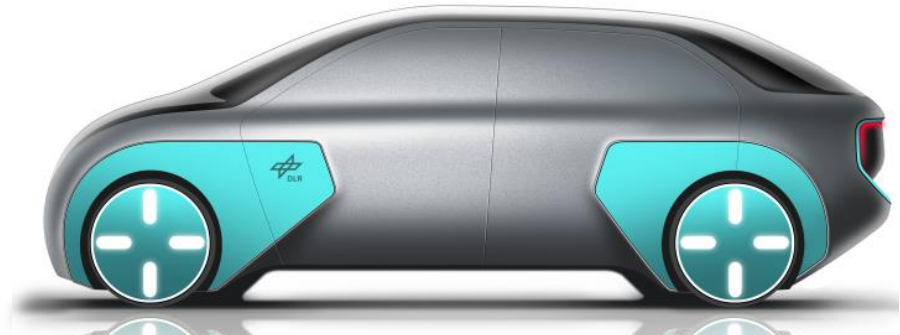

Comfortable fuel cell vehicle with CFRP body

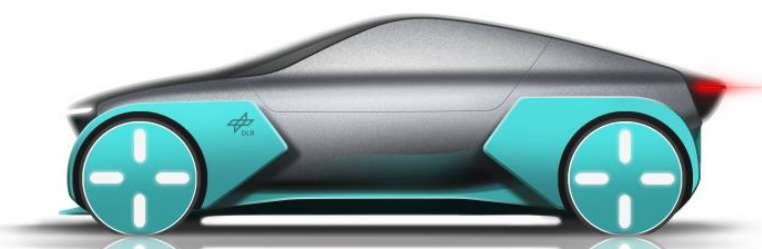

Cost-effective, very light and safe vehicle, class L7e

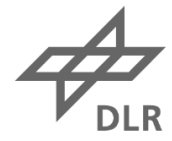




\section{DLR Next Generation Car (NGC) Concept: Urban Modular Vehicle}

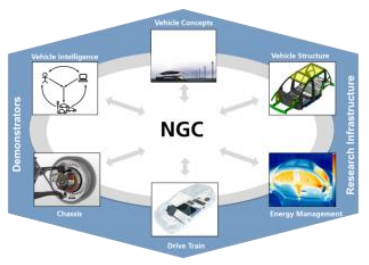

- The UMV is a intelligent and safe electric vehicle for urban use area for tomorrow's mobility.

- An example of the modularity of the UMV is the possibility of different derivatives on one modular system:

UMV Basic

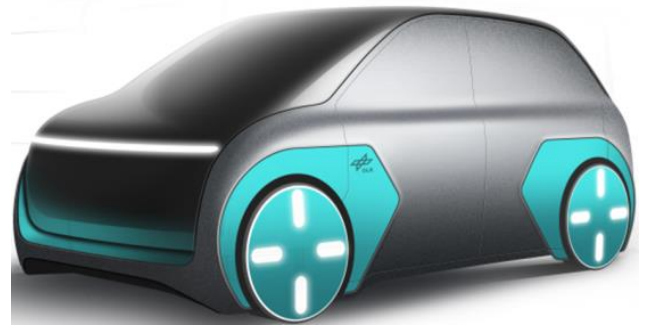

UMV Long

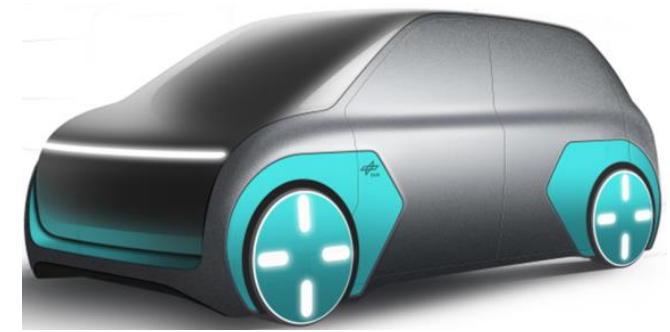

UMV Cargo

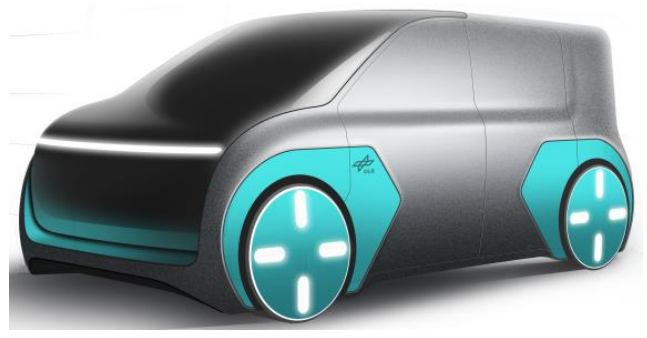

UMV Peoplemover

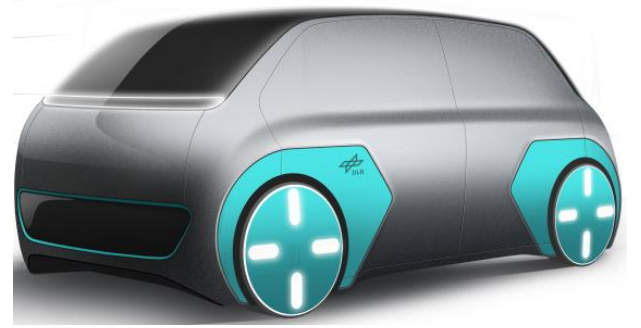

UMV Cargomover

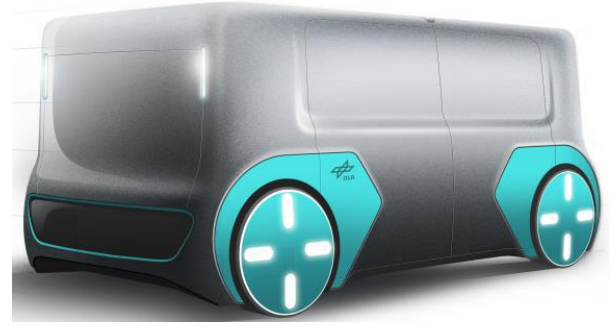




\section{DLR Next Generation Car (NGC) Concept Highlights: Urban Modular Vehicle}

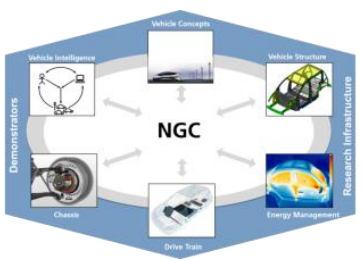

\section{Vehicle Intelligence}

- Several levels of automation, assist to fully automated and driverless selectable

- $360^{\circ}$ environment detection, C2X-networking

- Cooperation with the traffic

- ...

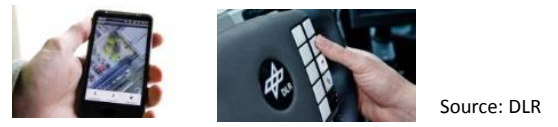

\section{Chassis}

- Modular, mechatronic, integrated lightweight chassis with innovative materials

- Steer-by-Wire-; Brake-by-wire,

- ...
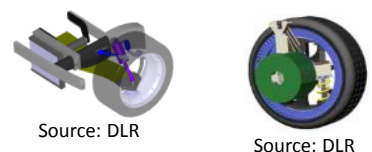

\section{Vehicle Concepts}

- Urban compact concept, intelligent, light and save
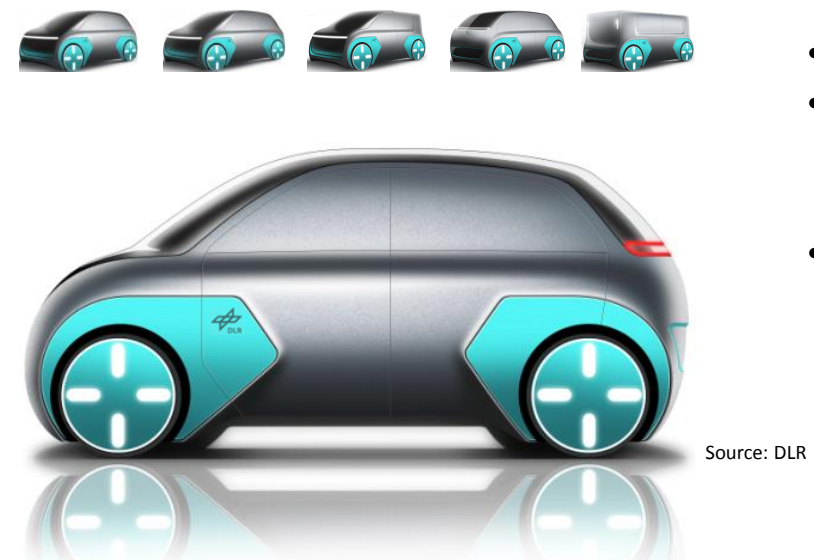

\section{Drive Train}

- The modular electric drive with $2 x$ $25 \mathrm{~kW}$ for the basic model, with high speed spreading on the rear axle

- PCM-energy storage

- $\cdots \sqrt{\text { sersoses }}+\infty$

\section{Vehicle Structure}

- Vehicle empty weight $680 \mathrm{~kg}$

- Optimized structures specifically for battery-electric vehicle in the sense of purpose design ...

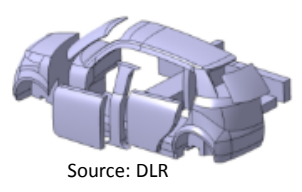

\section{Energy Management}

- Intelligent overall vehicle energy management

- Connection of heat and mass flows, Cabine-, battery-, electric motormanagement

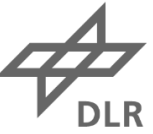




\section{Phase 1: Vehicle concept phase}

\section{Vehicle concept parameters, first boundary conditions}

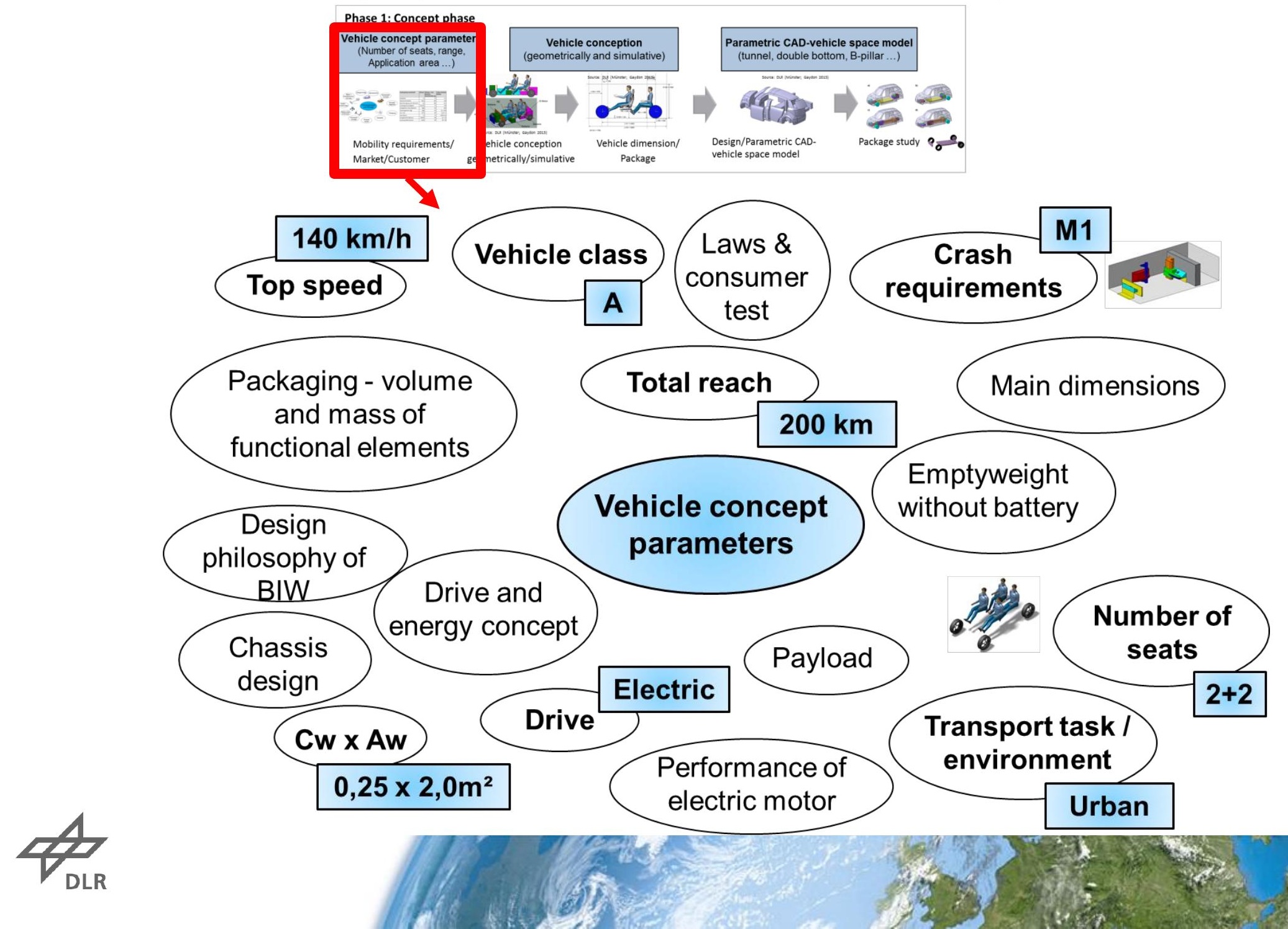




\section{Phase 1: Vehicle concept phase} Vehicle conception

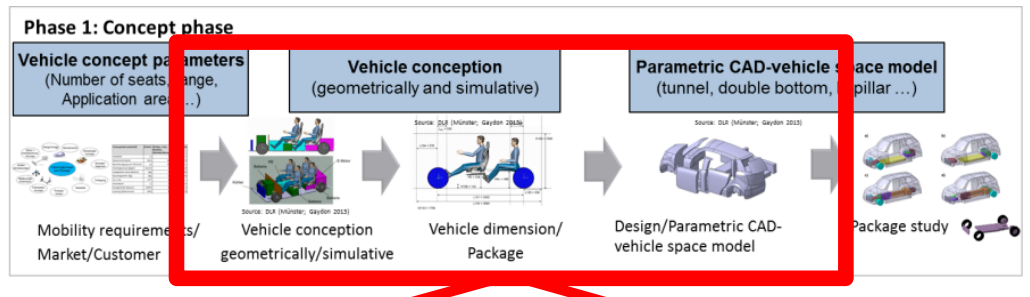

\section{Simulative part:}

the volume- and mass-intensive components are dimensioned with the aid of the driving resistance equation.

\section{Geometric part:}

the dimensions of the passenger compartment and the front/rear of the vehicle are estimated.
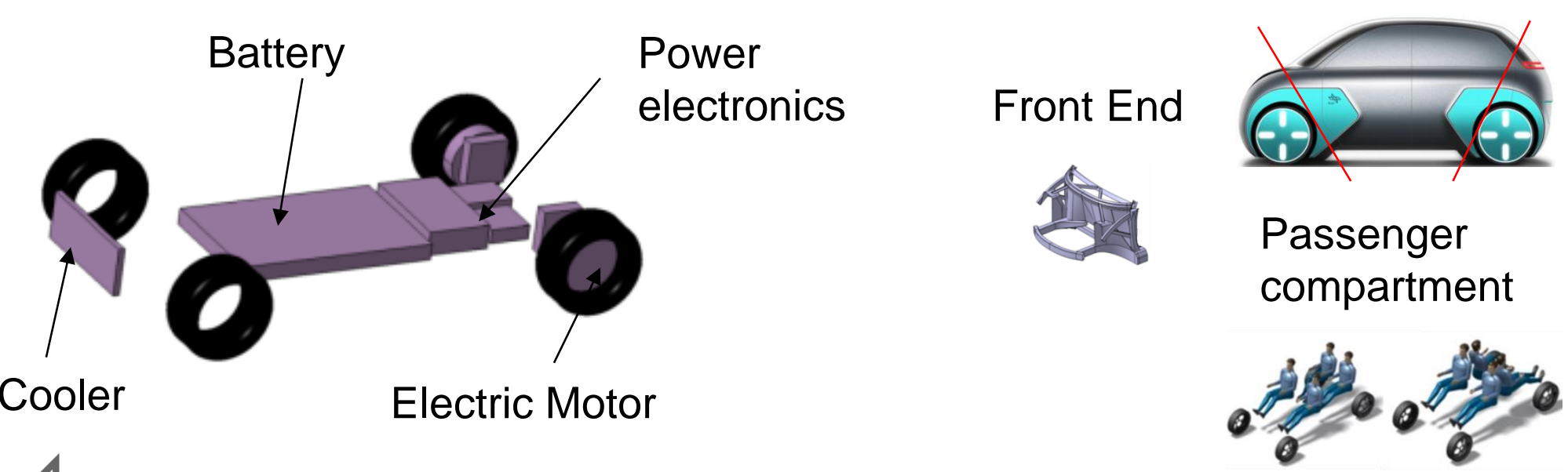

Rear End

Electric Motor

Cooler
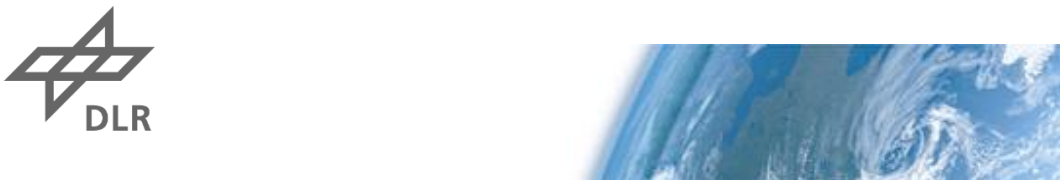


\section{Phase 1: Vehicle concept phase} Vehicle CAD-Modell
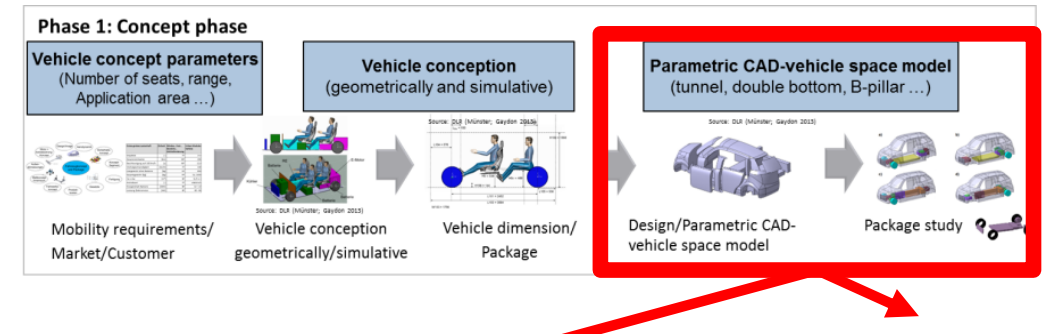

Parametric CAD-vehicle space model

Analysis and evaluation of different package variants in urban space model
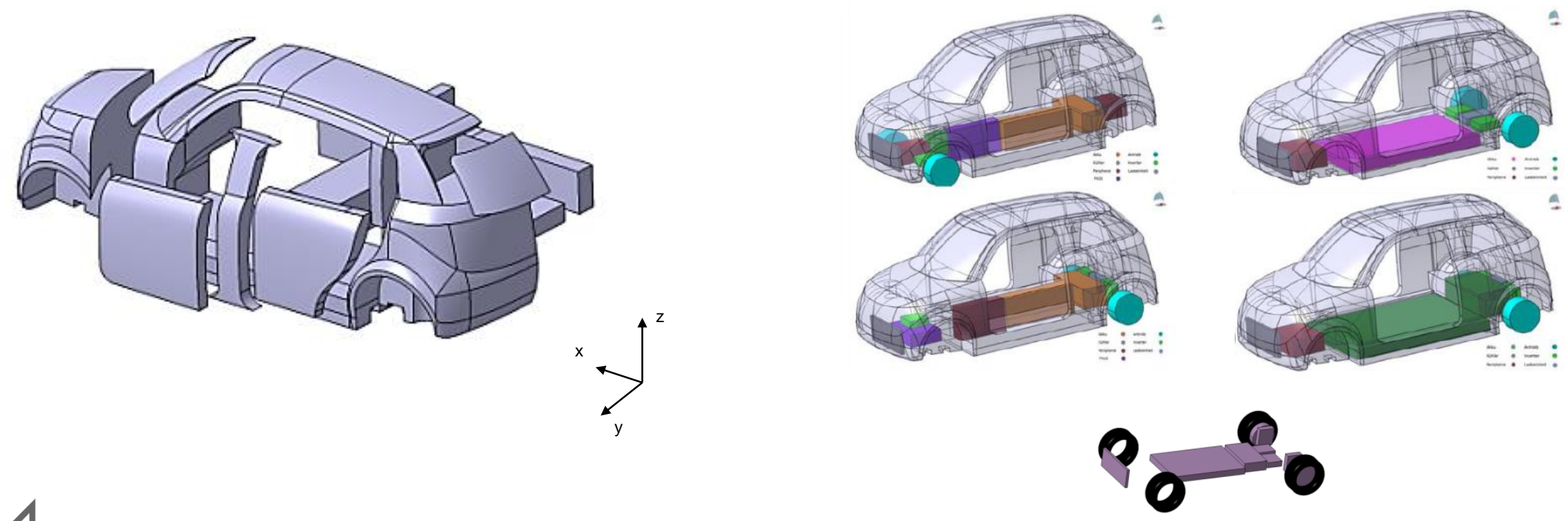


\section{Holistic development Methodology for vehicle concepts and body structures}

\section{Phase 1: Concept phase}

Vehicle concept parameters
(Number of seats, range,
Application area ...)

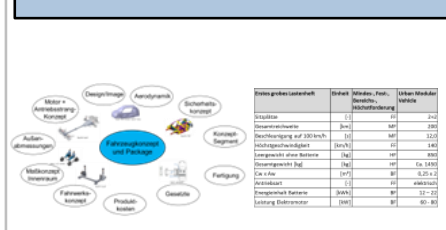

Mobility requirements/

Market/Customer

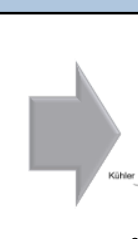

$$
\text { Source: DLR (Münster; Gaydon 2013) }
$$

Vehicle conception

geometrically/simulative

\section{Vehicle conception}

(geometrically and simulative)

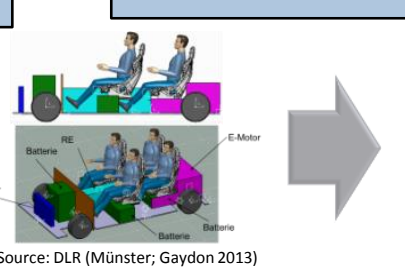

Vel

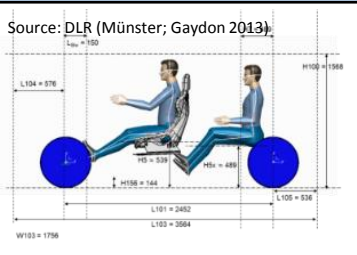

Vehicle dimension/ Package

\section{Parametric CAD-vehicle space model \\ (tunnel, double bottom, B-pillar ...)}

\section{Phase 2: Body structure development phase}

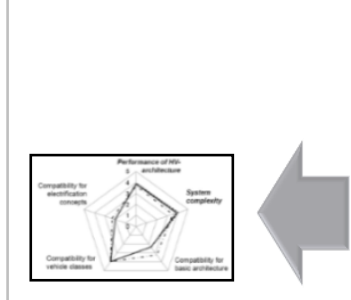

Overall Rating validation

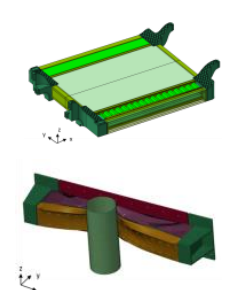

$<$
Design/Parametric CADvehicle space model

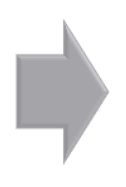

Package study

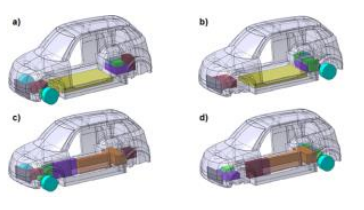

(1)

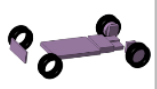

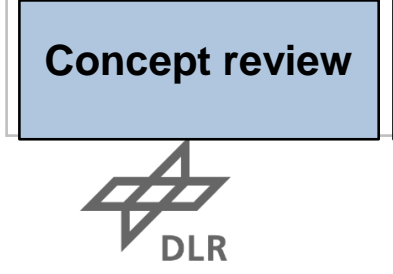

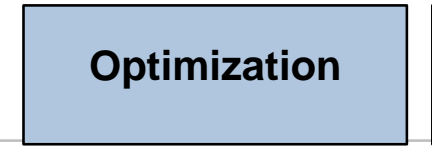

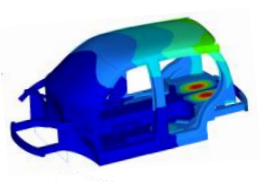

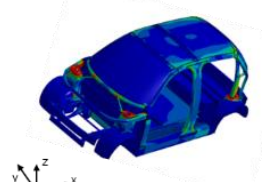

$\mathrm{V}^{2}$

Material selection, MDO optimization with concept body structure

\section{Concept body structure}

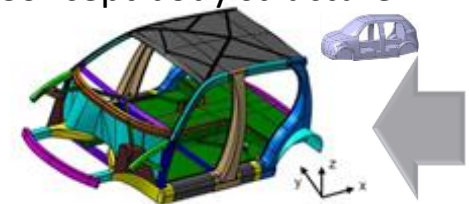

V1 tunnel + profile + shell

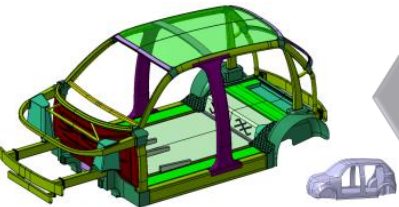

V2 without tunnel + profile + functionally integrated sandwich structures
Load path analysis
Topology optimization for global load pathfinding

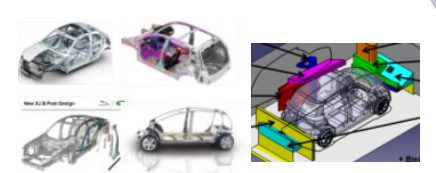

State of the art comparison

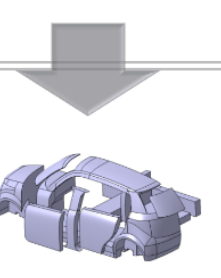

Selection of Basic form variant and package

$$
\begin{aligned}
& \text { V1 ID + } \\
& V 2 \text { IIC }+\because
\end{aligned}
$$
Component validation

\section{Engineering design}




\section{Phase 2: Body structure development phase}

Topology optimization on space model for global load pathfinding

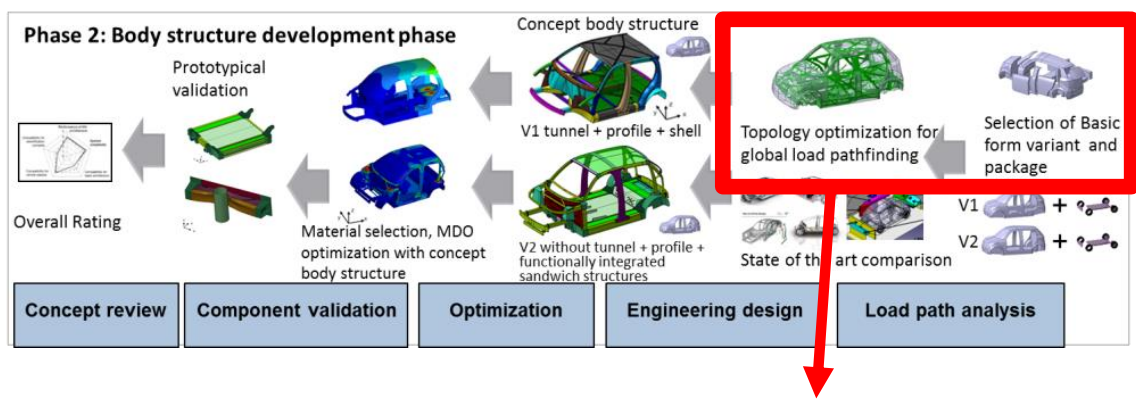

Topology optimization in different space model variants
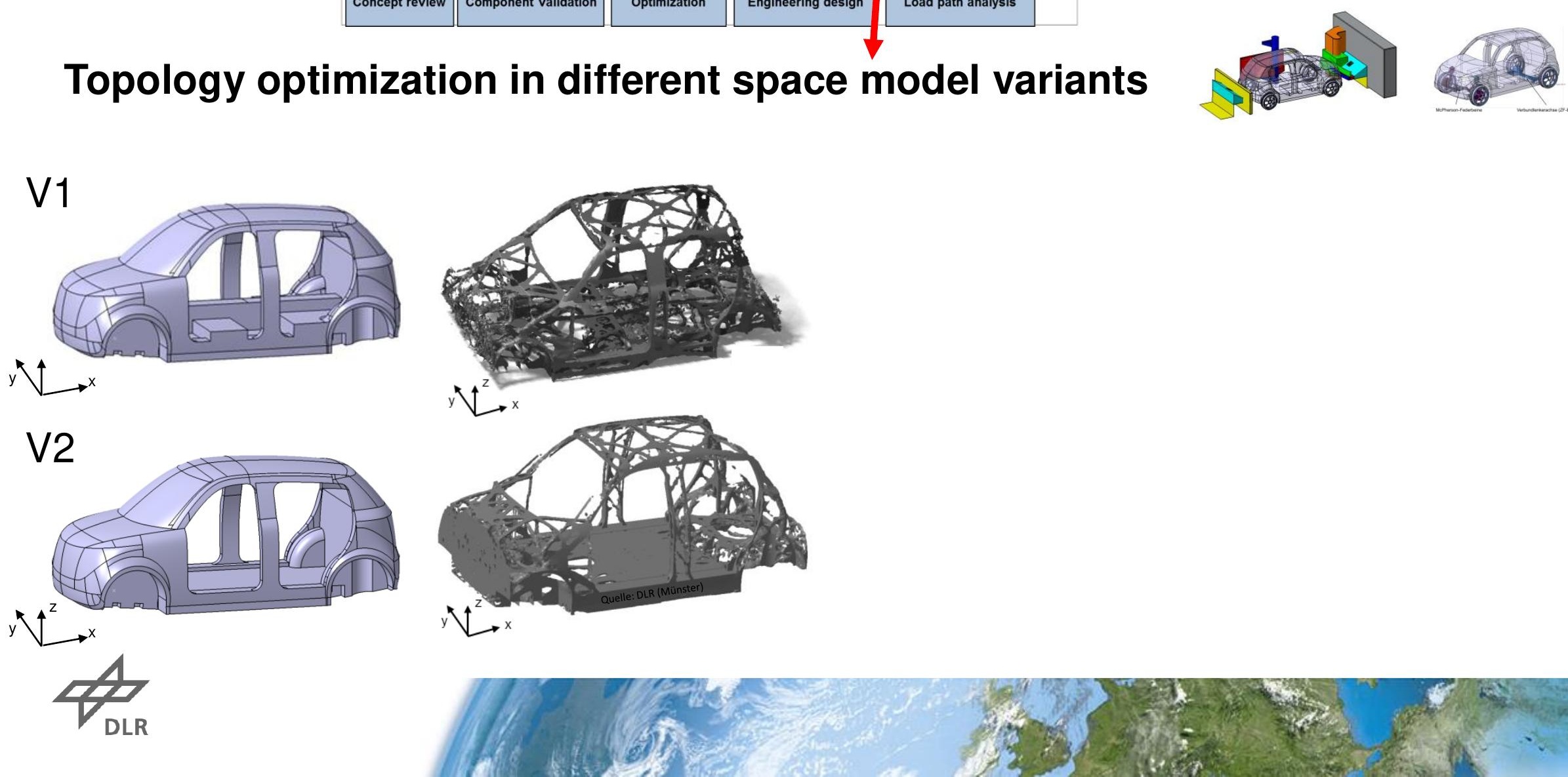
Phase 2: Body structure development phase Development of the vehicle body structure

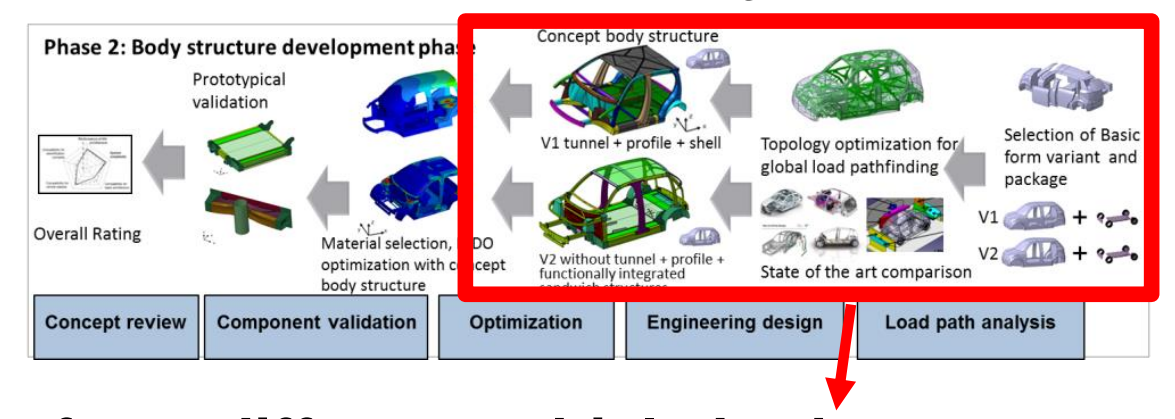

Development of two different vehicle body structures
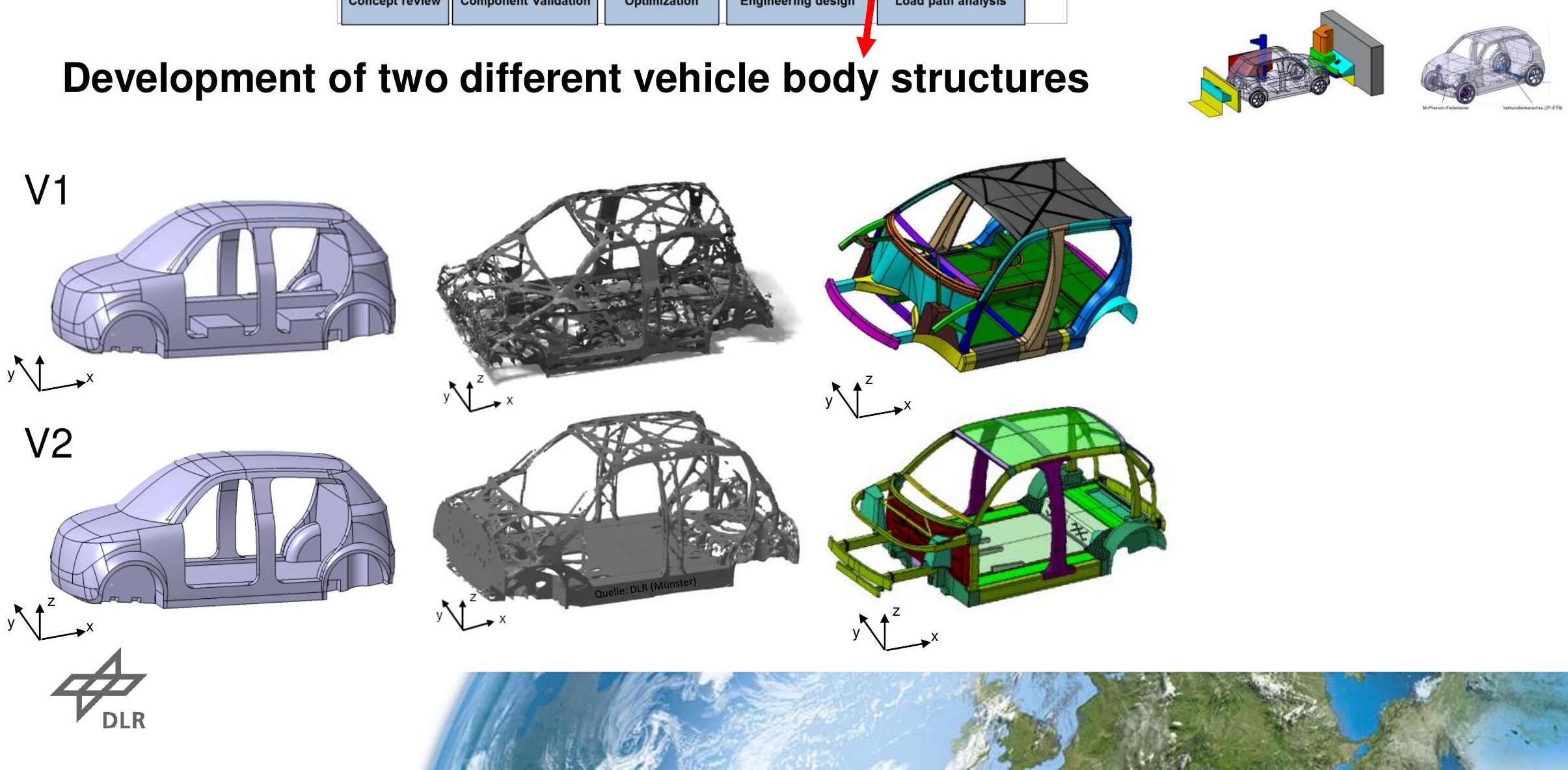


\section{Phase 2: Body structure development phase}

Development of the vehicle body structure

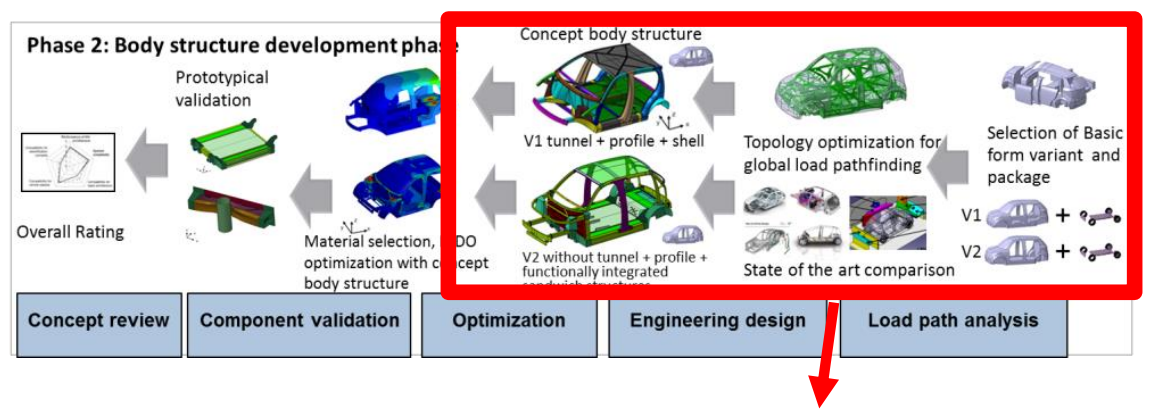

Static analysis of vehicle body structures
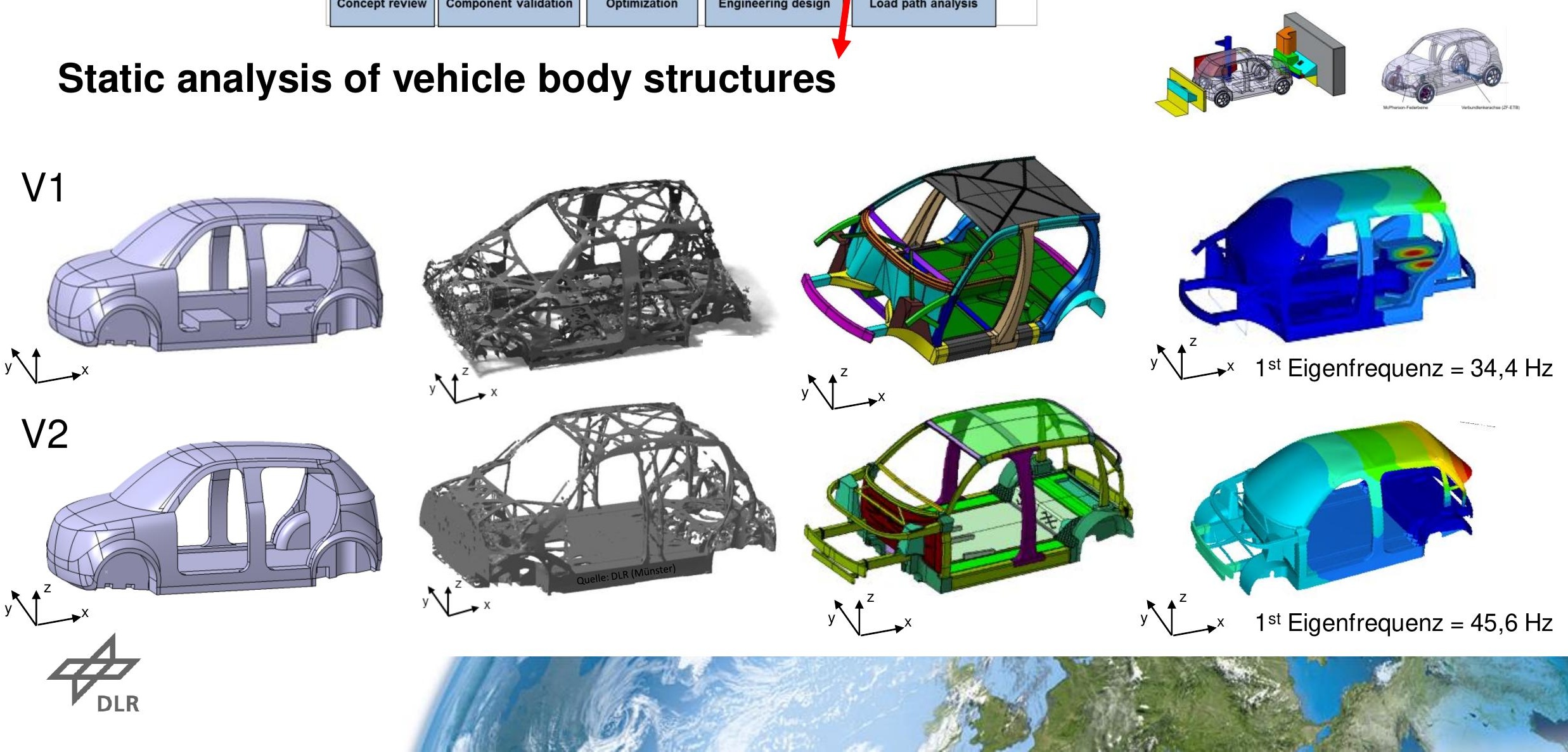


\section{Phase 2: Body structure development phase} Design philosophy

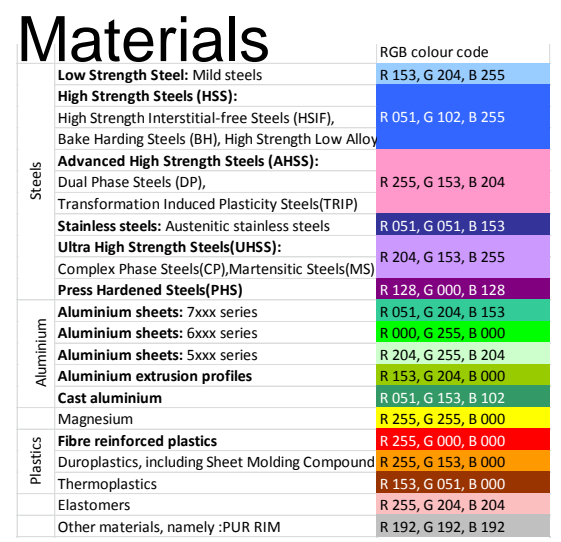

\section{Design philosophy BIW}

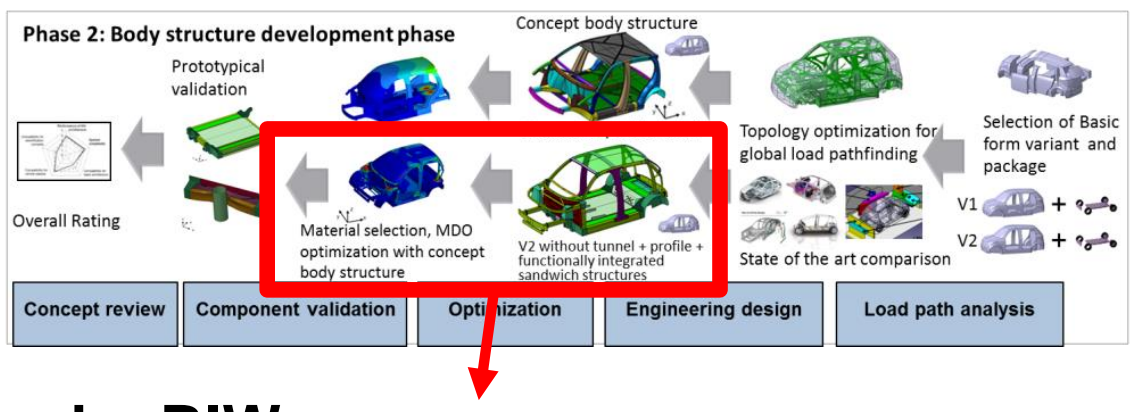

Node elements

- Cast nodes

- Adaptive node

- Combination of different materials

- modularising

- Function integration

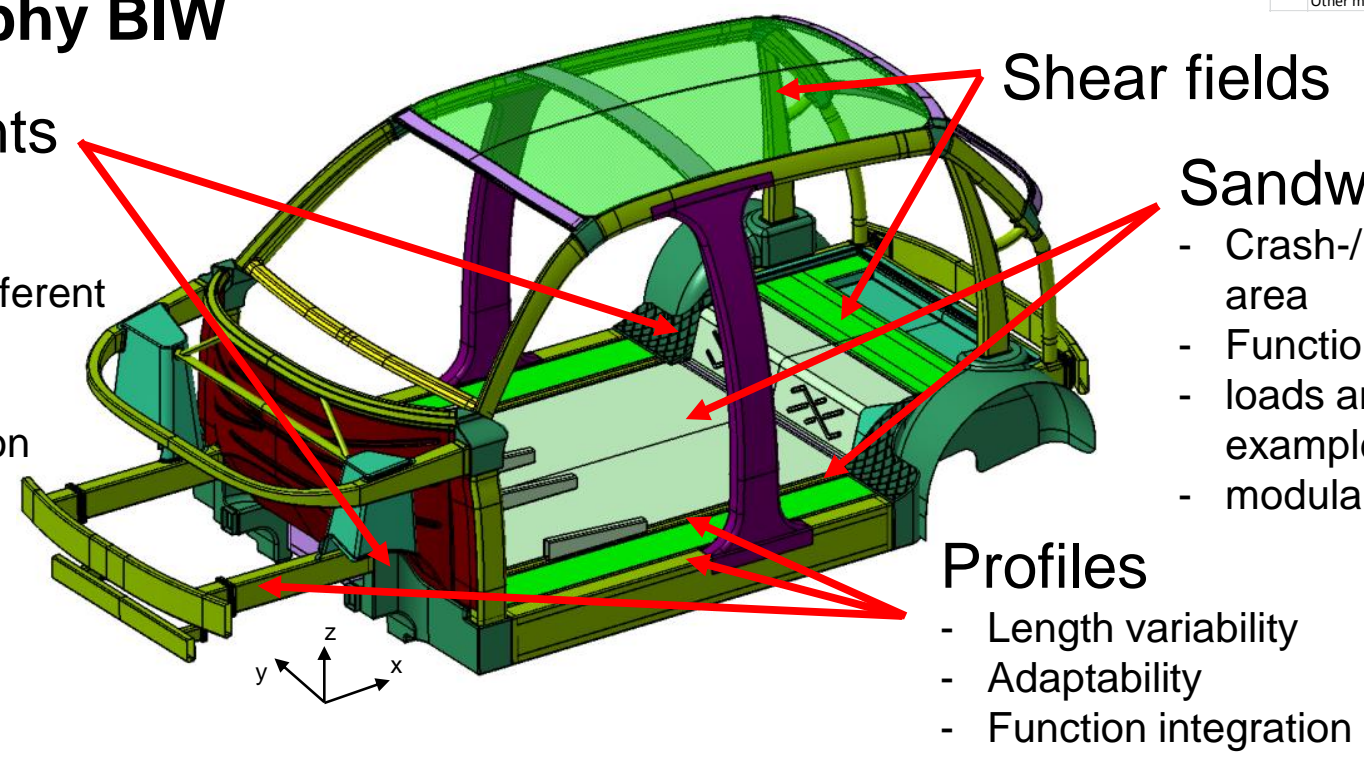

Aluminum intensive frame structure with profiles and nodes with functionally integrated sandwich surfaces and flat components in FRP 


\section{Phase 2: Body structure development phase Design philosophy \\ Materials}
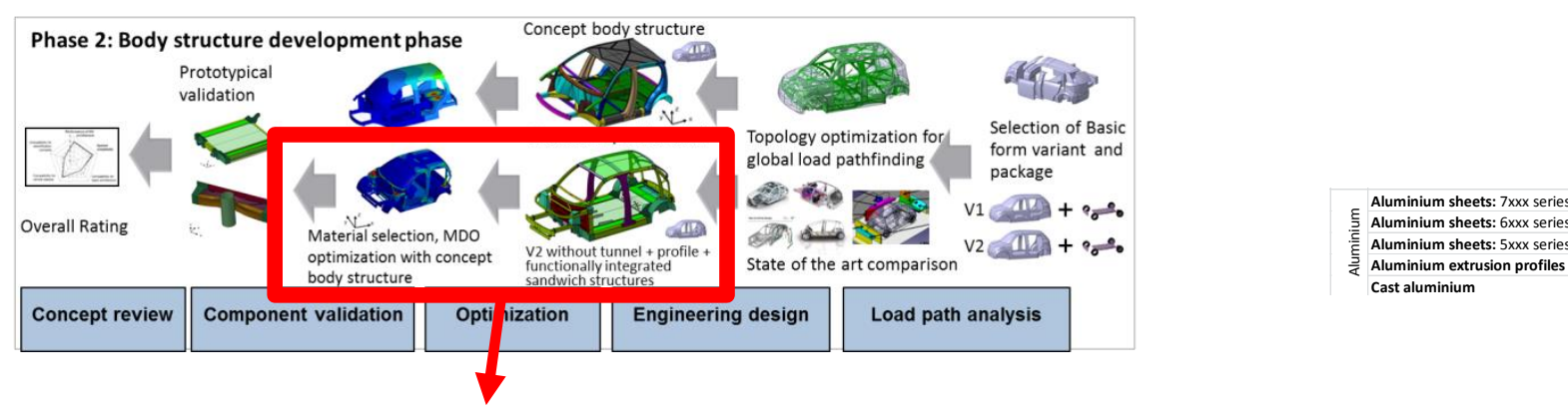

Design philosophy floor concept
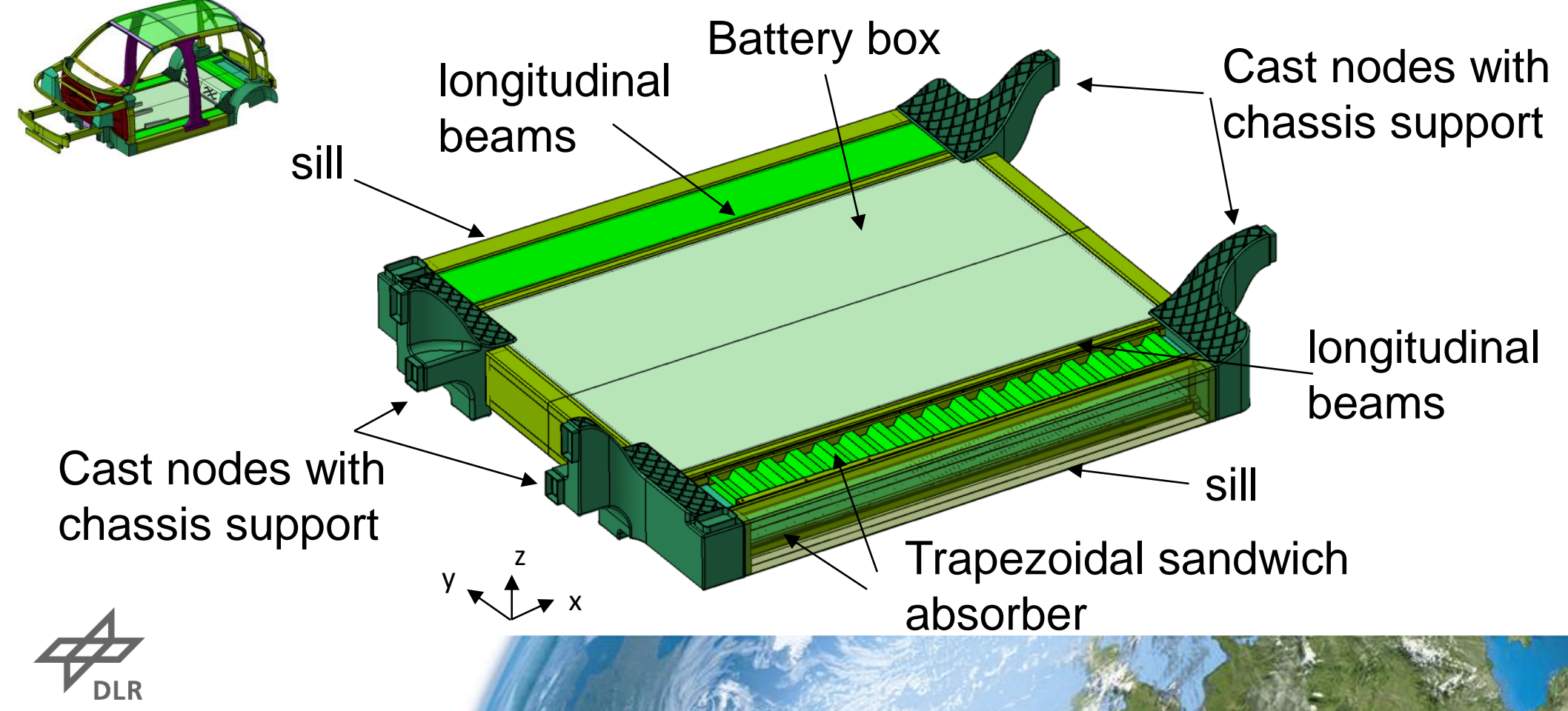


\section{Phase 2: Body structure development phase Design philosophy}

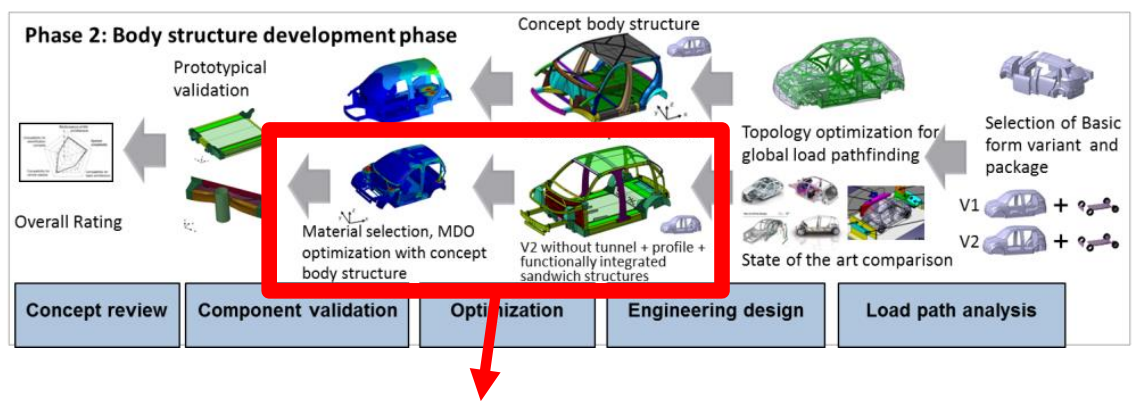

Modularity of the body in white:
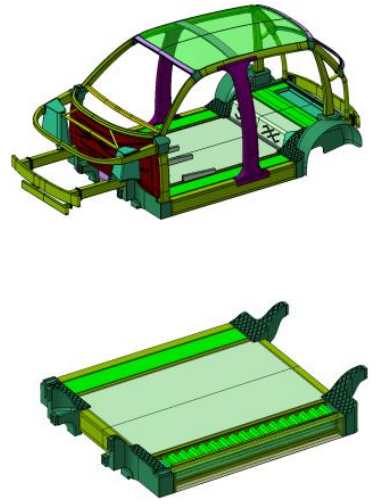

- Length variability

- Drive variability

- Chassis variability

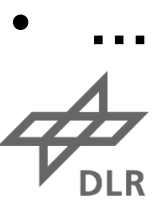

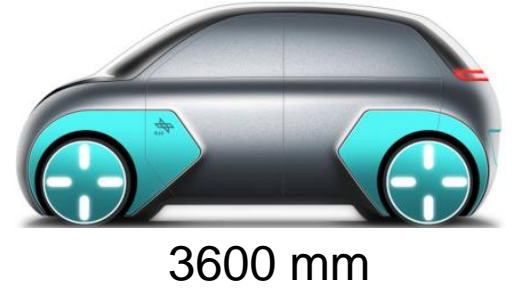
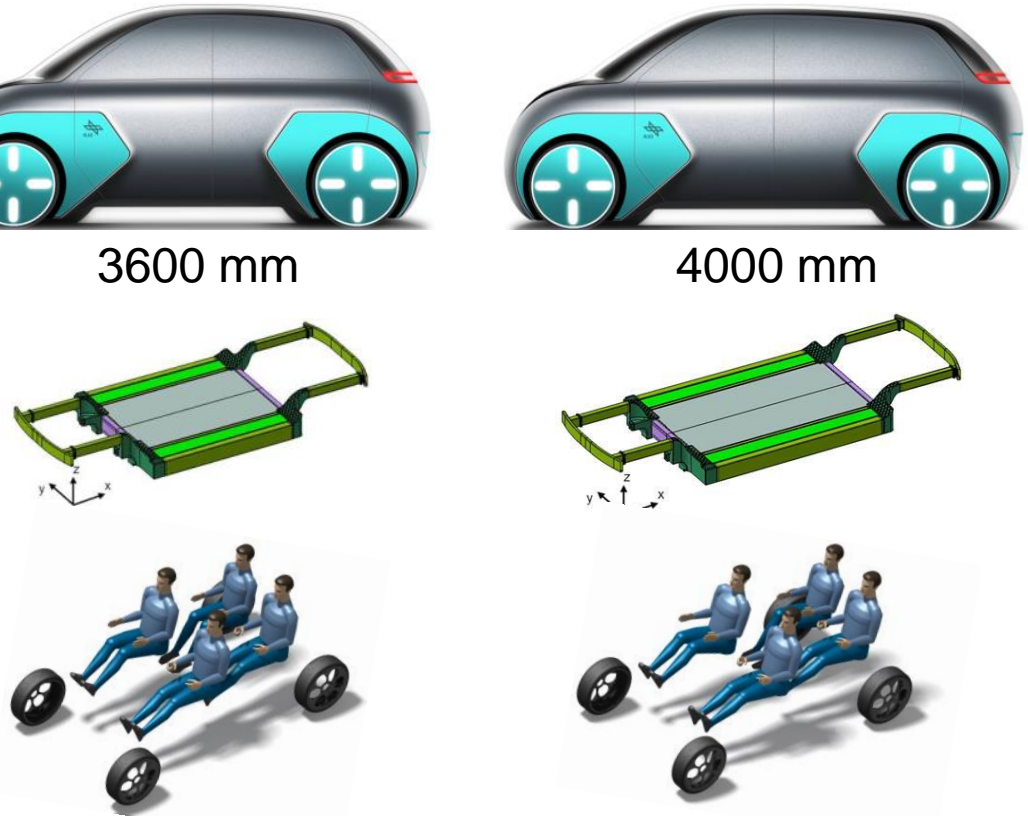
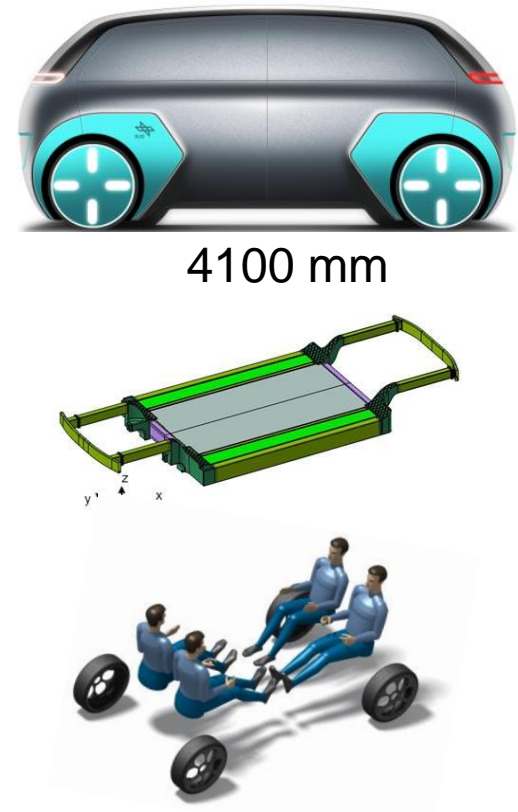


\section{Phase 2: Body structure development phase} Prototypical validation of the floor crash concept
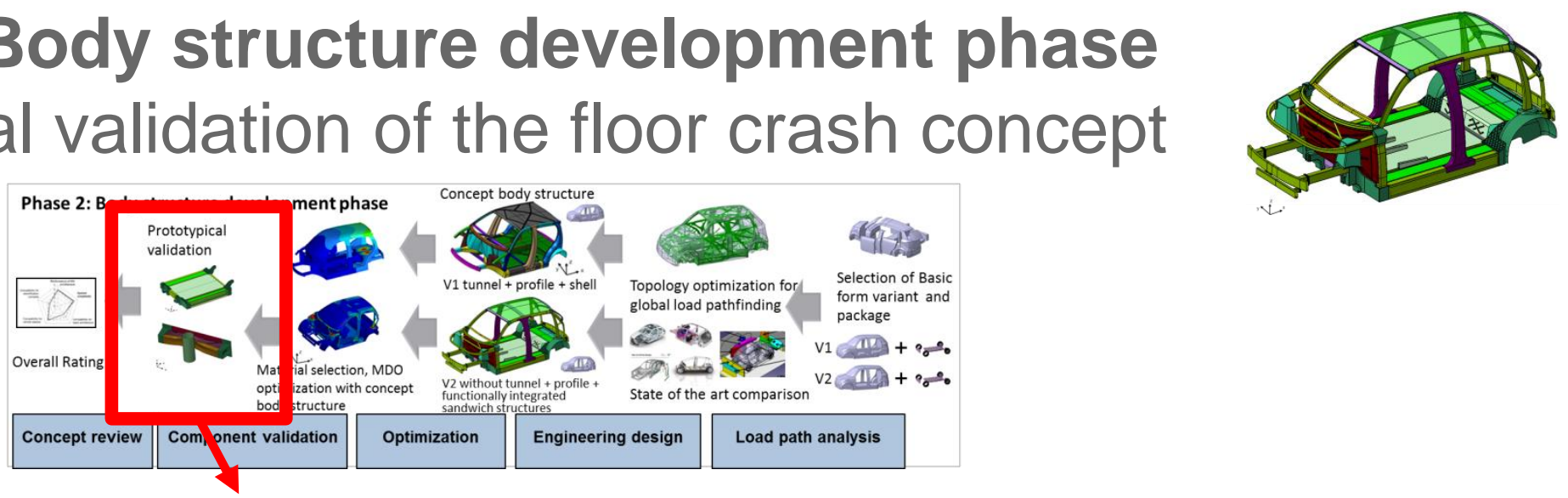

Levels of prototypical validation of the floor crash concept:

\begin{tabular}{|l|l|l|l|}
\hline Simulation & Complete vehicle & Component & $\begin{array}{c}\text { Floor crash } \\
\text { concept }\end{array}$ \\
\hline Experiment & & & \\
\hline
\end{tabular}

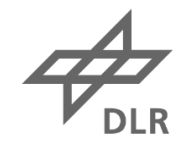




\section{Phase 2: Body structure development phase} Complete vehicle crash simulation
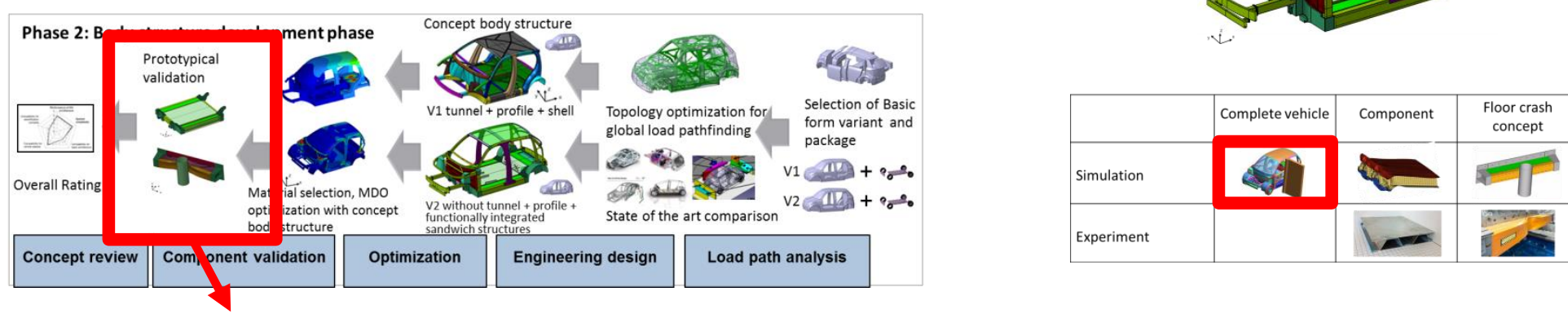

Complete vehicle crash simulation

- Vehicle mass $984 \mathrm{~kg}$

- Euro NCAP Pole-crash

- $\mathrm{v}=29 \mathrm{~km} / \mathrm{h}$

\section{Objectives:}

- Dimensioning of the BIW

- Review of the new body concept

\section{Results:}

- Crash concept of bottom crash module works

- No intrusion of the battery module
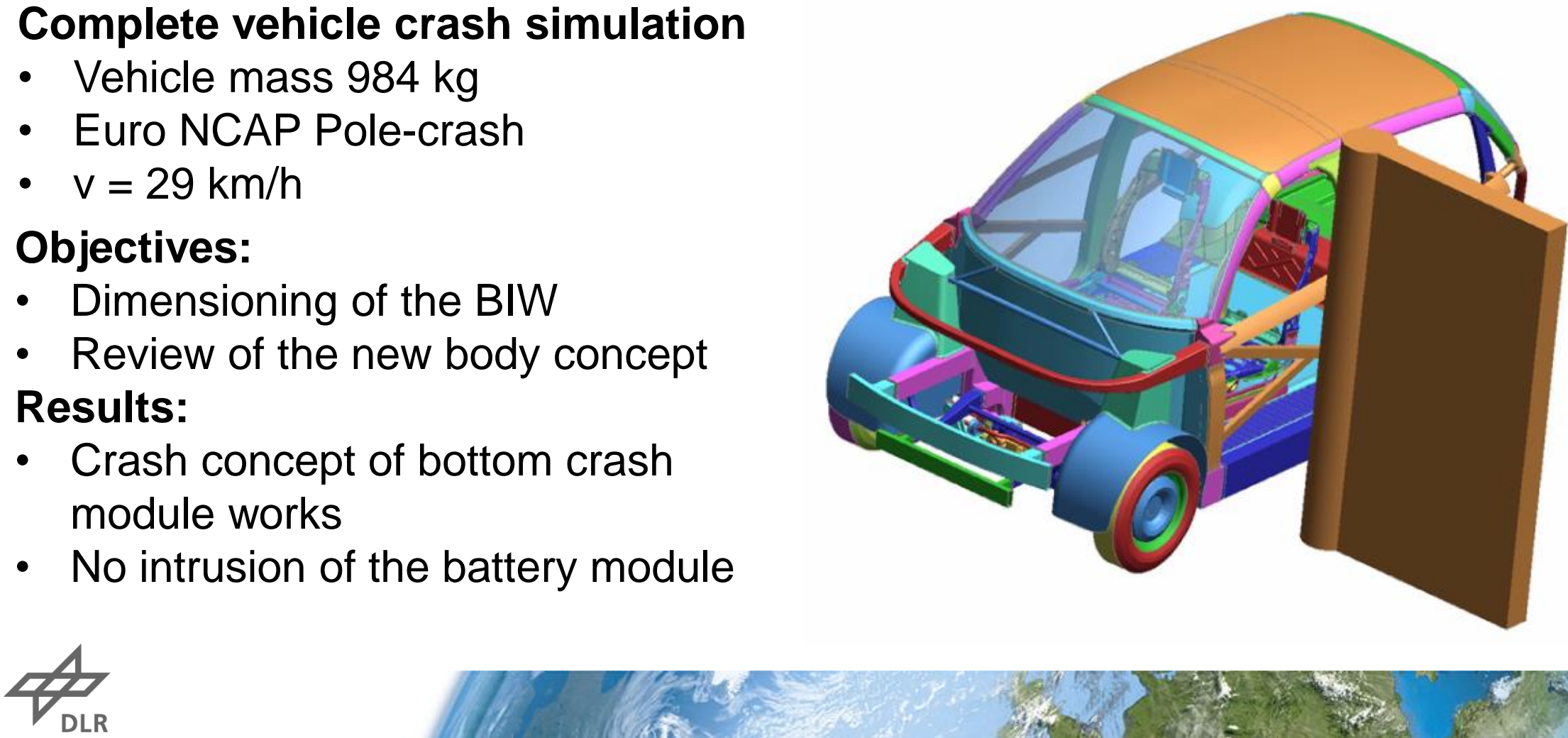


\section{Phase 2: Body structure development phase} Component simulation and experiment
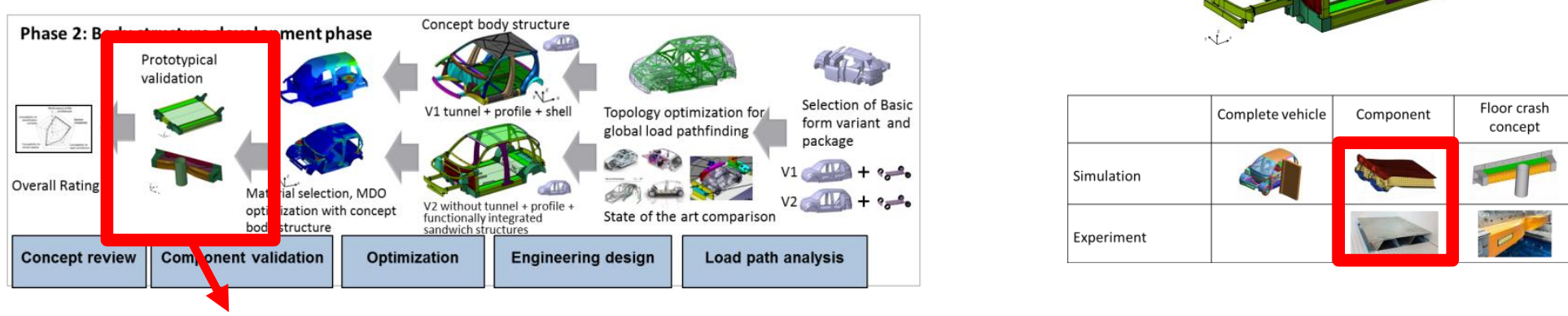

Component: Trapezoidal sandwich

Force peak $\approx 83 \mathrm{kN}$

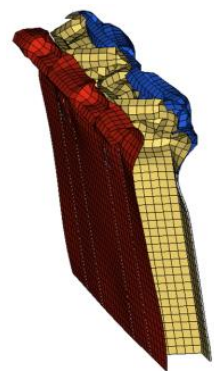

Simulation

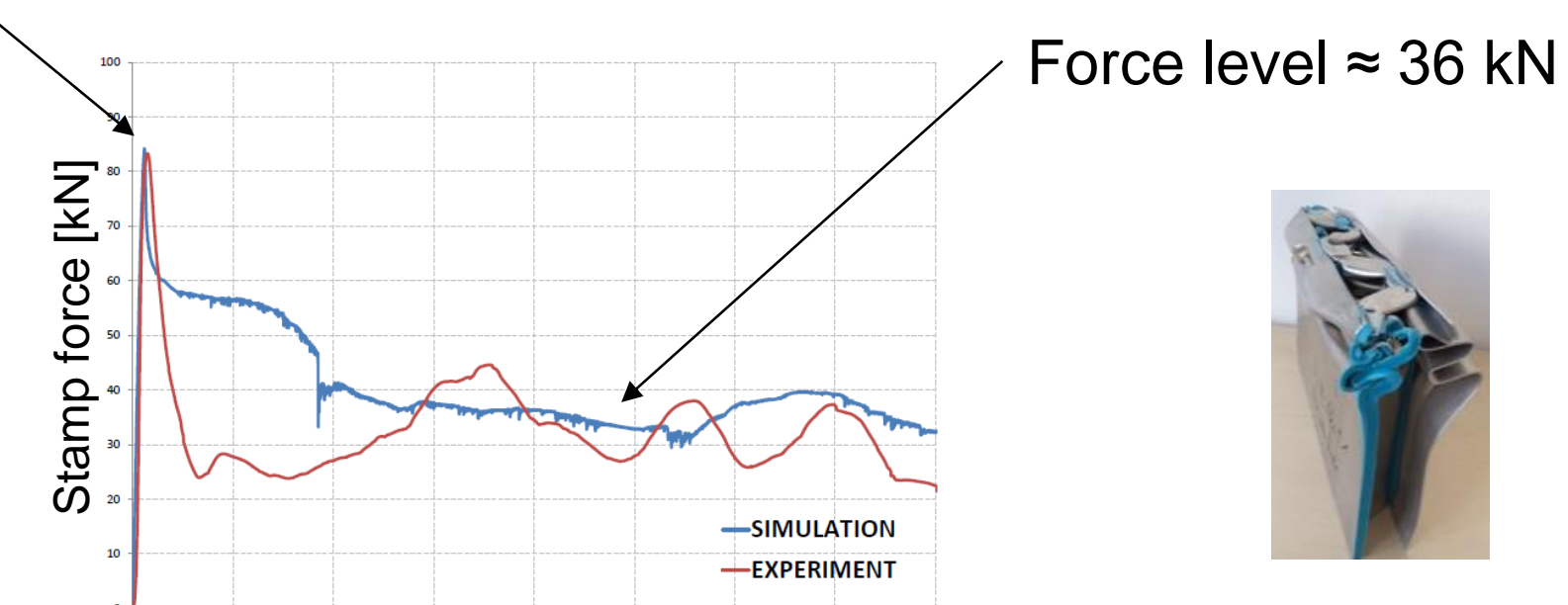

Stamp displacement [mm]
Experiment

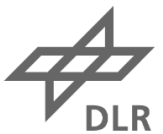




\section{Phase 2: Body structure development phase} Floor crash concept simulation
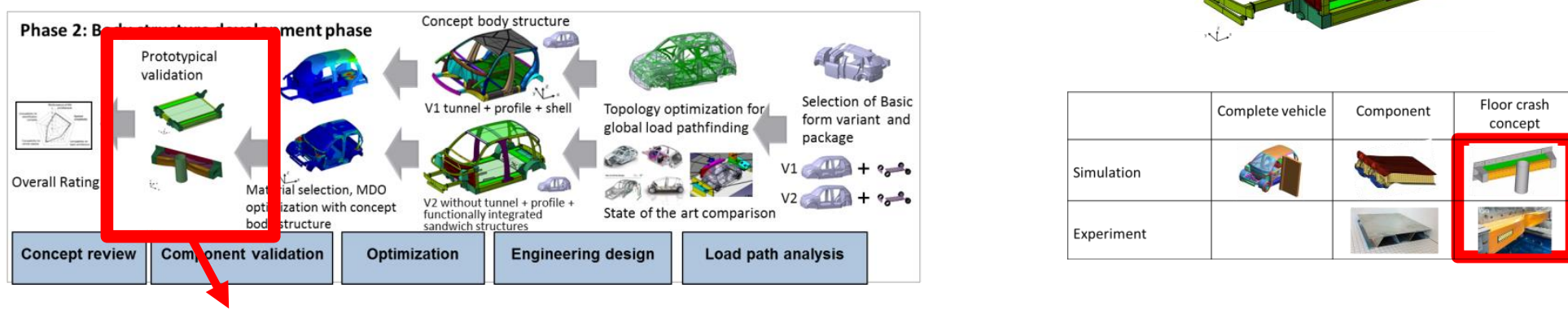

\section{Simulation: Complete crash concept of the floor module}

- Impact-mass 750 kg

- Euro NCAP Pole-crash

- $v=29 \mathrm{~km} / \mathrm{h}$

Force peak $\approx 242 \mathrm{kN}$
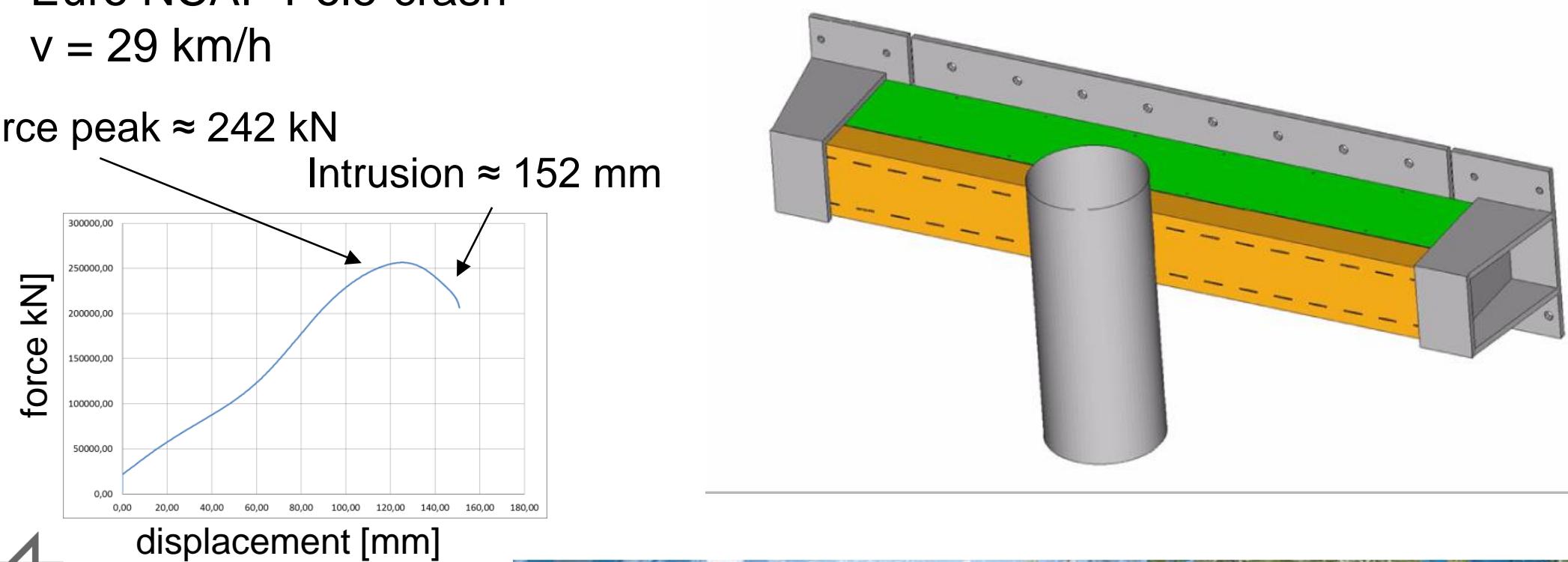

displacement [mm] 


\section{Phase 2: Body structure development phase} Floor crash concept experiment
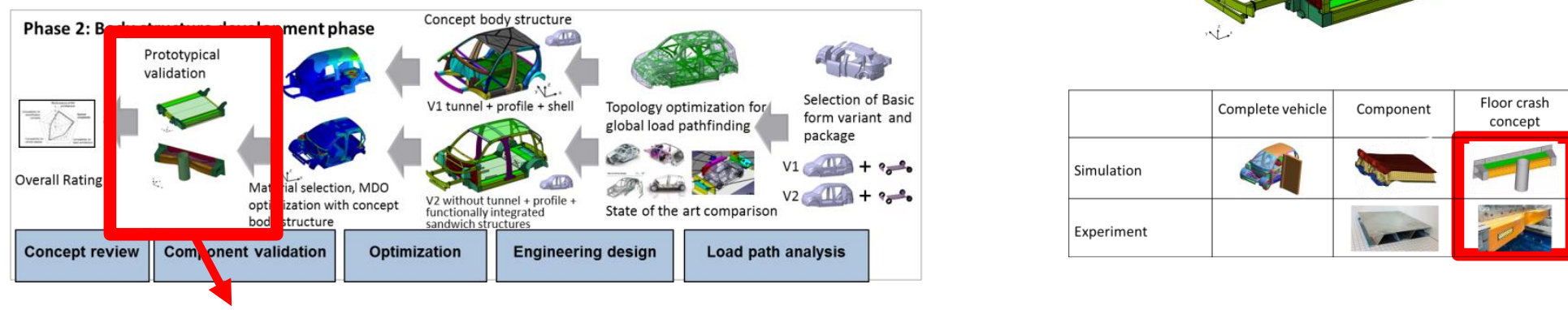

Experiment: Complete crash concept of the floor module

- Impact-mass $750 \mathrm{~kg}$

- Euro NCAP Pole-crash

- $\mathrm{v}=29 \mathrm{~km} / \mathrm{h}$

Force peak $\approx 237 \mathrm{kN}$
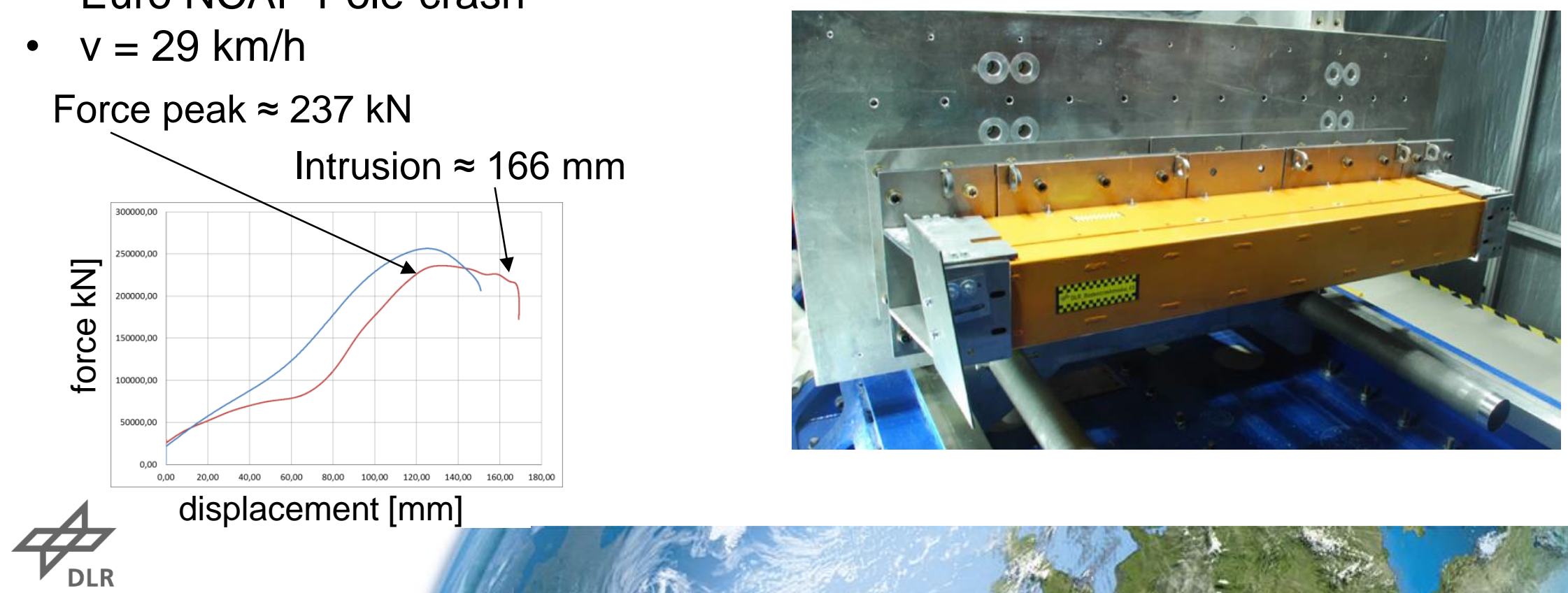

displacement $[\mathrm{mm}]$ 


\section{Phase 2: Body structure development phase} Floor crash concept simulation and experiment
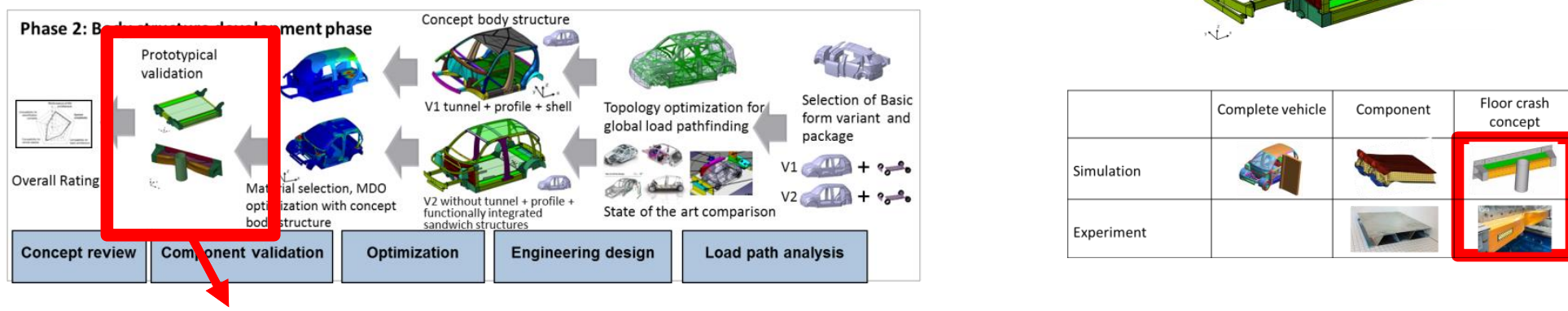

Comparison: simulation and experiment crashmodul

- Impact-mass $750 \mathrm{~kg}$

- Euro NCAP Pole-crash

- $v=29 \mathrm{~km} / \mathrm{h}$

Result:

- good correspondence simulation and experiment e.g. intrusion $166 \mathrm{~mm}$

Simulation

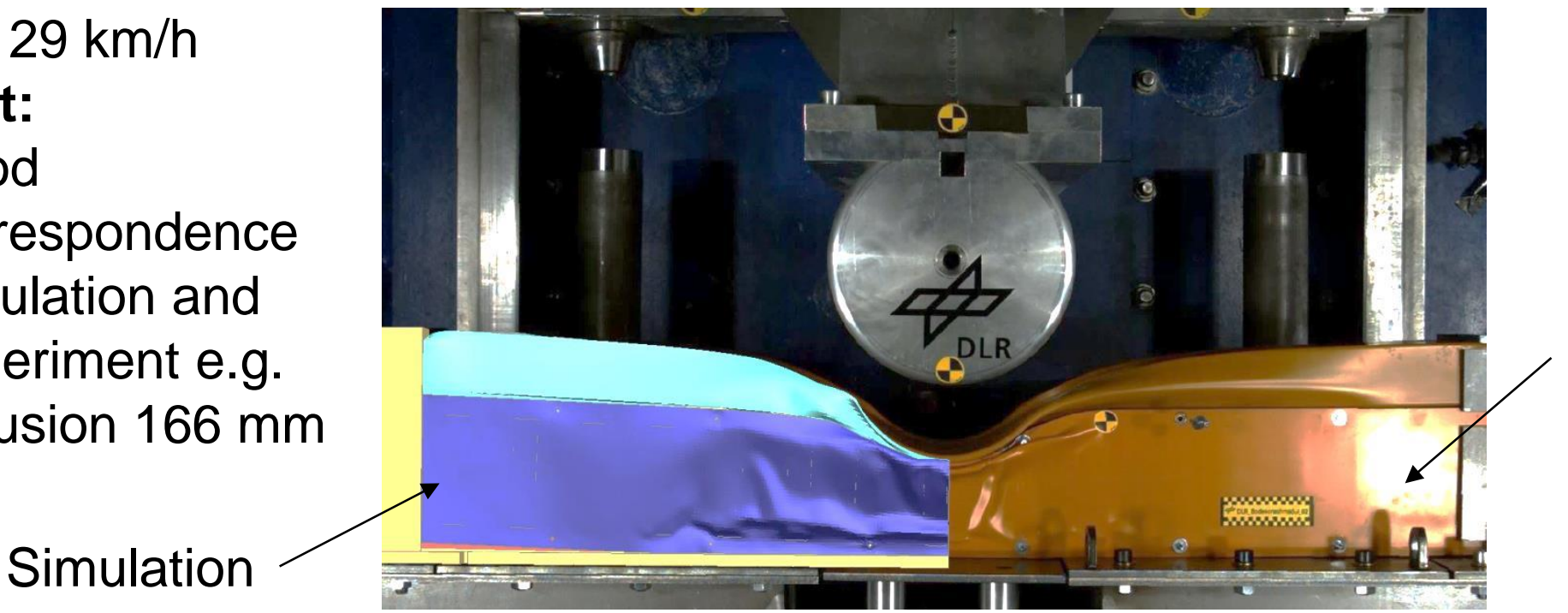

Experiment

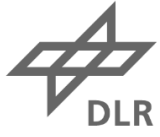




\section{Summery and outlook}

\section{Summery:}

- Holistic development Methodology for vehicle concepts and body structures

- Development of two different vehicle body structures

- Complete vehicle crash simulation

- Prototypical validation of the floor crash concept

- Complete crash of a novel floor module

\section{Outlook:}

- Detailing the entire body structure and virtuel simulation/optimization

- Prototypical validation other body in white components

- Prototypical construction of complete vehicle structure

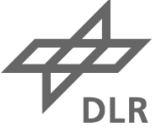




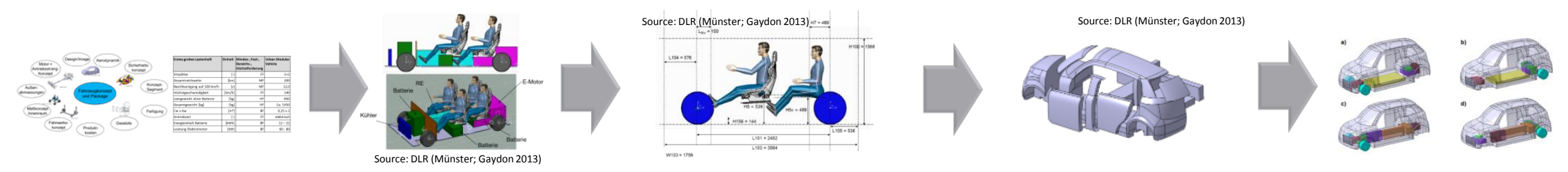

\section{Thank you for your attention}
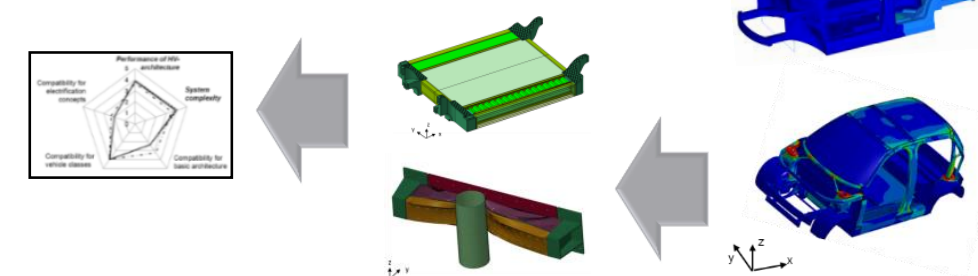
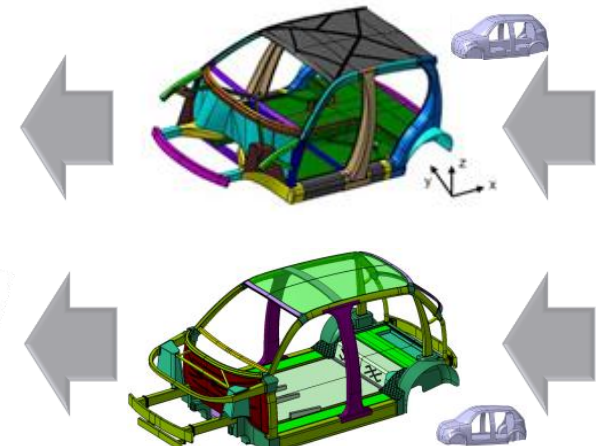
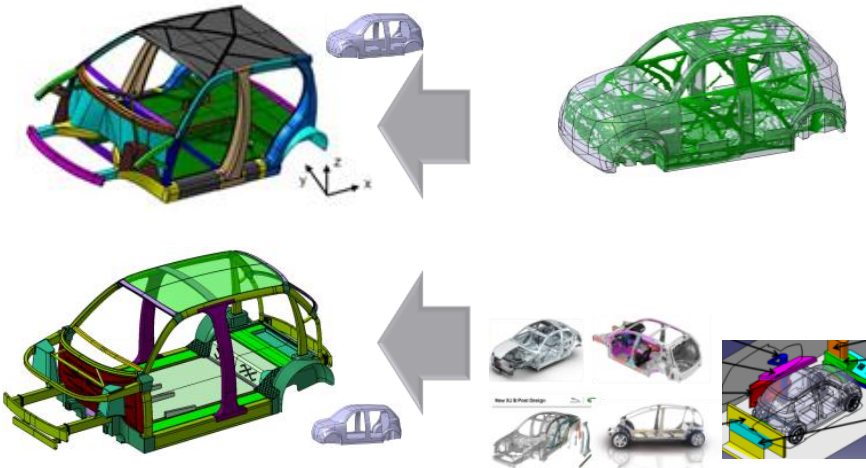

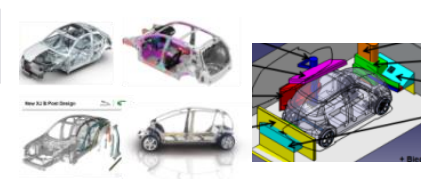

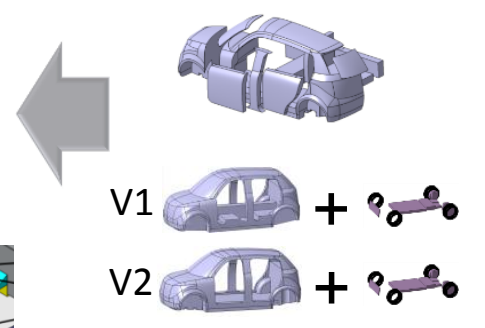

\section{Marco Münster}

Deutsches Zentrum für Luft- und Raumfahrt e.V. (DLR)

German Aerospace Center

Institute of Vehicle Concepts | Lightweight and Hybrid Design Methods | Pfaffenwaldring 38-40 | 70569 Stuttgart | Germany

Dipl.-Ing. Marco Münster

Phone +49 711 6862-707 | Fax +49 711 6862-258 | marco.muenster@dlr.de www.DLR.de/fk/en

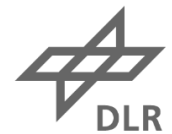

